\title{
Bacterias anaerobias: procesos que realizan y contribuyen a la sostenibilidad de la vida en el planeta
}

\author{
Anaerobic bacteria: processes they perform and their contribution to life \\ sustainability on the planet \\ Lucia Constanza Corrales MSc ${ }^{1}$, Diana Marcela Antolinez Romero², Johanna Azucena Bohórquez Macías², Aura Mar- \\ cela Corredor Vargas ${ }^{2}$
}

\section{Resumen}

Objetivo. Se realiza una revisión sobre los aspectos degradativos de materia orgánica, obtención de energía y nutrientes de las bacterias anaerobias. La importancia de estos microorganismos es el papel que desempeñan en los procesos que contribuyen al mantenimiento de la vida misma. Dentro del metabolismo para la descomposición de macromoléculas, estos microorganismos realizan varios procesos: hidrólisis, acetogénesis y metanogénesis, entre otros, cobija reacciones que se realizan dependiendo de las características particulares de la bacteria y de las funciones que cumplen dentro del ciclo degradativo, para la obtención de nuevos productos dependiendo de las rutas bioquímicas o procesos fermentativos que allí se desarrollan.

Palabras clave: bacterias anaerobias, rutas bioquímicas, hidrólisis, acetogénesis, metanogénesis.

\begin{abstract}
Objective. A review of the degradation aspects of organic matter, obtaining energy and nutrients from anaerobic bacteria is performed. The importance of these organisms is the role they play in the processes contributing to the maintenance of life itself. Within the metabolism for the decomposition of macromolecules, these microorganisms perform several processes: hydrolysis acetogenesis and methanogenesis, among others, it covers reactions performed depending on the particular characteristics of the bacteria and of the roles in the degradative cycle for development of new products depending on the biochemical pathways or fermentation processes that take place there.
\end{abstract}

Keywords: anaerobic bacteria, biochemical pathways, hydrolysis, acetogenesis, methanogenesis.

\footnotetext{
Docente investigadora. Universidad Colegio Mayor de Cundinamarca. Bogotá, Colombia.

2. Estudiantes Programa de Bacteriología y Laboratorio Clínico, Facultad de Ciencias de la Salud. Universidad Colegio Mayor de Cundinamarca. Bogotá, Colombia.

Correspondencia: lcorrales@unicolmayor.edu.co ORCID: 0000-0002-2398-348X

Recibido: 06/10/2015 Aceptado: 11/11/2015
} 


\section{Introducción}

Las bacterias anaerobias cuentan con un metabolismo que genera su energía a partir de sustancias que carecen de oxígeno, lo hacen generalmente a través de procesos de fermentación, aunque en ocasiones, como en el caso de las que se encuentran en grietas hidrotermales marinas a grandes profundidades, que lo hacen mediante reacciones que emplean compuestos químicos inorgánicos.

Estudios estiman que la vida se inició en el planeta hace unos 3800 millones de ańos; durante los primeros 2000 a 2500 millones de ańos estuvo poblado exclusivamente por comunidades bacterianas, que a través de su evolución lograron cambiar las condiciones de la tierra, favoreciendo así, la posterior aparición de formas de vida más complejas (1), además la diversificación evolutiva de las bacterias condujo a la aparición de las formas de nutrición que hoy existen. La actividad secuencial y acompasada de las bacterias fotosintéticas, heterótrofas, saprofitas y quimiosintéticas permitió y permite que la materia se recicle y pueda seguirse utilizando indefinidamente (2). El desarrollo de todas estas formas de nutrición tuvo, por tanto, como consecuencia un hecho trascendental: se cerraron los ciclos biogeoquímicos del planeta, con lo que la vida pudo perpetuarse a expensas de la energía solar $(1,3,4)$.

Muchos consideran a las bacterias como organismos insignificantes y carentes de interés, manejando un discurso referido a ver en ellas un conjunto de agentes infecciosos a los que hay que combatir porque hacen daño (1). Sin embargo, la comunidad científica ha comenzado a tener una mirada diferente acerca del mundo bacteriano, ya que se conocen los procesos metabólicos que desarrollan y las aplicaciones de estos para el beneficio de la sostenibilidad de la vida y finalmente se comprende que tienen mucho que enseñar, por algo son los habitantes más viejos de la Tierra (3). El hecho de que hayan sido capaces de sobrevivir a todas las grandes catástrofes planetarias, que han acarreado la extinción masiva de muchas especies de mayor tamaño y, en apariencia, de mayor capacidad e importancia, hace volver sobre la grandeza y complejidad de estos seres tan pequeños $(2,4)$.

La actividad metabólica de los diversos grupos bacterianos da lugar a la formación de distintos microambientes en los que cada grupo va a encontrar los más adecuados a sus necesidades y va a estar protegido de factores ambientales potencialmente tóxicos (altos niveles de oxígeno, alta intensidad de luz, exposición a la radiación ultravioleta, desecación, estrés osmótico etc.). Estas asociaciones facilitan el intercambio de nutrientes, gases y metabolitos, y reflejan un estilo de vida mutualista y sinérgico, donde el crecimiento, la reproducción y los ciclos biogeoquímicos son llevados a cabo de forma más eficiente que en poblaciones aisladas $(2,3)$. En la Figura 1 se hace una diferenciación de los diferentes procesos de digestión que puede llevar una bacteria siendo aerobia o anaerobia.

La vida en comunidad permite que los desechos, que genera un grupo de bacterias, se conviertan en nutrientes y posibilite condiciones ambientales aptas para el desarrollo de otros grupos bacterianos. Con frecuencia se observa que estas comunidades, que están en todos los espacios naturales, se disponen en láminas estratificadas, en las que las bacterias fotosintéticas, productoras de oxígeno y materia orgánica como las cianobacterias, se sitúan en la parte superior con mayor exposición a la luz solar; debajo de éstas se sitúan las bacterias heterotróficas aerobias, consumidoras de oxígeno y materia orgánica, y las bacterias quimioautotróficas, que necesitan oxígeno para oxidar los compuestos, como el amonio, de donde obtienen la energía necesaria para sintetizar su propia materia orgánica (5). La actividad de estas bacterias, que consumen oxígeno, origina condiciones anaerobias en las capas más profundas, donde van a residir los distintos grupos de bacterias anaerobias (6). 
Procesos metabólicos de las bacterias anaerobias

El proceso fermentativo de las bacterias anaerobias comprende una serie de procesos, que interactúan entre sí, en una serie de reacciones metabólicas complejas en ausencia de oxígeno, haciendo parte importante de los ciclos biogeoquímicos del carbono, nitrógeno y azufre, entre otros (7). estos procesos metabólicos se han divido en 3 grupos o etapas principales: 1) hidrólisis y fermentación, 2) acetogénesis y 3) metanogénesis; la primera etapa del proceso involucra la hidrólisis de sólidos insolubles, es decir partículas orgánicas (celulosa o hemicelulosa) o coloides orgánicos (proteínas), en compues- tos solubles simples que pueden ser absorbidos a través de la pared celular, para que posteriormente, dichas moléculas hidrolizadas sean catalizadas por bacterias fermentativas en alcoholes y ácidos grasos, teniendo como resultado de este proceso, la producción de hidrógeno y dióxido de carbono. luego, durante la acetogénesis, se produce ácido acético a través de la oxidación de ácidos grasos de cadena corta o alcoholes o a través de la reducción del $\mathrm{CO}_{2}$, usando hidrógeno como donador de electrones para la reacción (7). El último paso que corresponde a la $m$ metanogénesis, es llevada a cabo por arqueas, las cuales obtienen su energía de la conversión de un número restringido de sustratos a metano (8).

\section{Procesos químicos de la digestión}

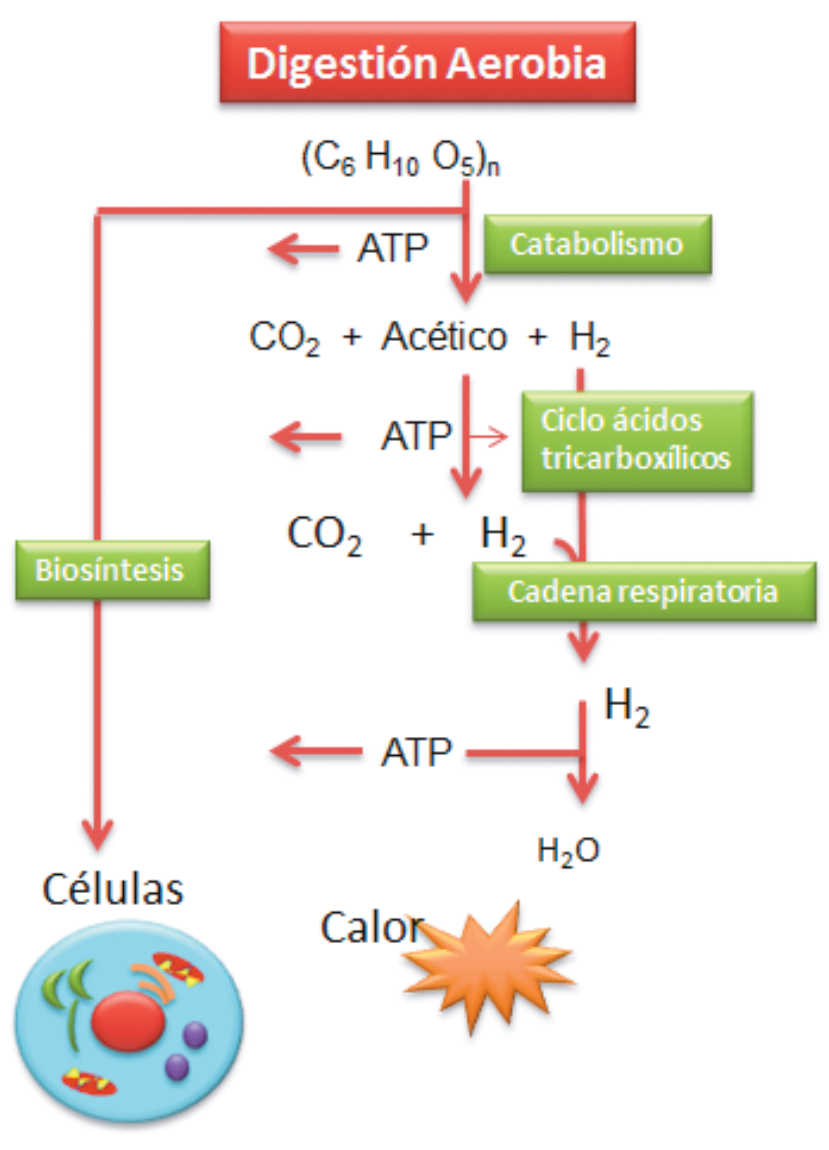

\section{Digestión Anaerobia}

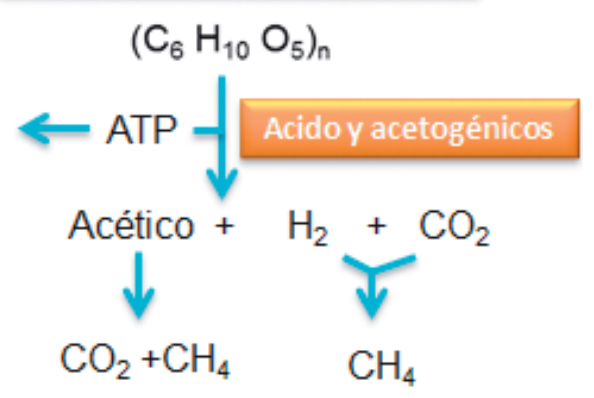

$\mathrm{CO}_{2}+\mathrm{CH}_{4} \quad \mathrm{CH}_{4}$

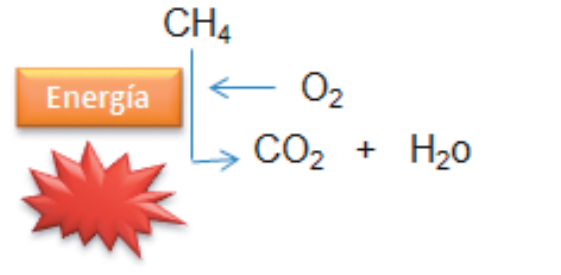

Figura 1. Comparación en los procesos químicos de digestión aerobia y anaerobia/.Corredor AM. Modificado de Schoberth 1984 (9). 
La digestión anaerobia es una fermentación microbiana en ausencia parcial o total de oxígeno que da lugar a una mezcla de gases, en los cuales principalmente se encuentra el metano y el dióxido de carbono. El producto principal obtenido de la digestión anaerobia es el biogás, mezcla gaseosa de metano en una proporción de 50 a $70 \%$ y dióxido de carbono $\left(\mathrm{CO}_{2}\right)$ de 30 a 50\%, con pequeñas cantidades de otros componentes como nitrógeno $(\mathrm{N})$, oxígeno $\left(\mathrm{O}_{2}\right)$, hidrógeno $(\mathrm{H})$, sulfuro de hidrógeno $\left(\mathrm{H}_{2} \mathrm{~S}\right)$, estos valores dependen tanto de los microorganismos que se encuentren presentes como del proceso en sí $(9,10)$.

Los procesos en donde las bacterias anaerobias hacen degradación se llevan a cabo en ausencia de oxígeno $\left(\mathrm{O}_{2}\right)$. Los microorganismos trabajan en serie o grupo para degradar la materia orgánica a través de etapas sucesivas, cada una desencadenando la siguiente (7). Los microorganismos anaerobios de importancia clínica obtienen principalmente su energía mediante la utilización de las vías fermentativas, en donde los compuestos orgánicos como los ácidos y alcoholes, entre otros, sirven básicamente como aceptores finales de electrones (11).

\section{Elementos en la digestión}

Las bacterias, en la realización de estos procesos, se ven condicionadas por algunos factores físicos y químicos, que posibilitan su adecuado desarrollo, estos factores son: cargas de materia orgánica, ácidos grasos volátiles, temperatura, alcalinidad, nutrientes y presencia de N y P, entre otros (12). La presencia de materia orgánica y la temperatura son fundamentales para el metabolismo de las bacterias, este último aspecto es un factor condicionante en las interacciones biológicas y de supervivencia que desarrollan las bacterias. En la Tabla 1 , se muestra los diferentes rangos de temperatura y algunos microorganismos anaerobios facultativos y anaerobios estrictos que hacen parte en cada uno de éstos $(12,13)$.

Tabla 1. Microorganismos anaerobios encontrados en diferentes rangos de temperatura.

Rango de temperatura en ${ }^{\circ} \mathrm{C}$

$10-15$

$20-30$

$30-37$

$42-46$

Termótrofos

Psicrótrofos

Mesófilos

Tipo de microorganismo

Psicrófilos

Bacillus spp

Clostridium spp

Clostridium spp

Methanococcus spp

Methanococcus $s p p$
Microorganismos encontrados

Methanobacterium spp

Methanobacterium spp

Clostridium spp

$50-80$

Termófilos

Lactobacillus spp

Thermus spp

Thermococcus spp 
Por otro lado, el pH influye en el crecimiento bacteriano, casi todas las bacterias muestran un crecimiento óptimo en un intervalo de $\mathrm{pH}$ de 6.5 - 7.5, en la Tabla 2. se muestran las escalas de $\mathrm{pH}$ y algunos microorganismos anaerobios asociados a estos (13).

Tabla 2. Microorganismos anaerobios encontrados en diferentes rangos de $\mathrm{pH}$.

$1.1-5.5$

$5.5-8.0$

Acidófilos

Neutrófilos

Lactobacillus spp

Bifidobacterium bifidum

Clostridium perfringes

Methanococcus sp

Methanobacterium sp

Propionibacterium acidipropionici

Clostridium botulinum

Clostridium sporongenes

$8.5-11.5$

Alcalonófilos

Clostridium tetani

Fusobacterium spp

Micrococcus spp

Durante el proceso anaerobio, hay ciertos factores que pueden afectar el pH en una reacción, como por ejemplo el ácido carbónico y los ácidos volátiles. Generalmente los rangos de $\mathrm{pH}$ de las bacterias están entre 6.0 y 7.5 y la capacidad que tiene el buffer, se muestra de una forma dependiente del sistema gas carbónico/alcalinidad, el cual, en equilibrio con la disociación del ácido carbónico, tiende a regular la concentración del ion hidrógeno así:

$$
\begin{aligned}
& \mathrm{CO}_{2}+\mathrm{H}_{2} \mathrm{OH}_{2} \mathrm{CO}_{3} \longleftrightarrow \mathrm{HCO}_{3}^{-}+\mathrm{H}^{+} \\
& \mathrm{HCO}_{3}{ }^{-}+\mathrm{OH}^{-} \longleftrightarrow \mathrm{CO}_{3}^{-2}+\mathrm{H}_{2} \mathrm{O}
\end{aligned}
$$

La capacidad buffer de los ácidos grasos volátiles sobre la alcalinidad ocurre en una franja de $\mathrm{pH}$ entre 3.75 y 5.75 , siendo por tanto de poca importancia en un proceso anaerobio (14).
Los nutrientes que utilizan las bacterias, generalmente, son tomados del ambiente en donde se desarrollan, por lo cual se dice que estos son tomados de la materia orgánica o inorgánica en donde se encuentren, por eso las bacterias anaerobias pueden crecer en presencia de N, P, S, C, entre otros compuestos (14). Como se ha mencionado anteriormente las bacterias interactúan entre sí en una serie de reacciones metabólicas en ausencia de oxígeno, haciendo parte importante de los diferentes ciclos biogeoquímicos.

\section{Bacterias sulfatoreductoras}

Las bacterias sulfatoreductoras son organismos anaerobios que pueden utilizar los sulfatos como aceptores finales en la respiración, reduciéndolo sin asimilarlo. Los sulfatos son las sales o los ésteres del ácido sulfúrico, contienen como unidad común un 
átomo de azufre en el centro de un tetraedro formado por cuatro átomos de oxígeno (15). Estas bacterias se pueden adaptar a diferentes lugares o situaciones y pueden ser encontradas en numerosos ambientes terrestres y acuáticos en los cuales se ha disminuido el oxígeno, debido a la descomposición aeróbica de la materia orgánica, esta adaptación de las bacterias en los diferentes ambientes se ve reflejada en las vías de interacción, Figura 2. En estos ambientes anaeróbicos, bacterias fermentadoras pueden extraer energía de las grandes moléculas orgánicas, dando como resultado pequeñas moléculas tales como ácidos orgánicos y alcoholes que son oxidados por acetógenos y metanógenos (16).

Estas bacterias se encuentran principalmente en ambientes anóxicos ricos en sulfatos. Han sido descubiertas en suelos, lodos de estuarios, en aguas dulces, de alcantarillado y marinas, salobres, termales y áreas geotermales, depósitos de sulfuro, en pozos petroleros y de gas, y en el intestino de mamíferos e insectos. Las bacterias reductoras de sulfato son comunes en entornos anaeróbicos en los que ayudan en la degradación de la materia orgánica (17).

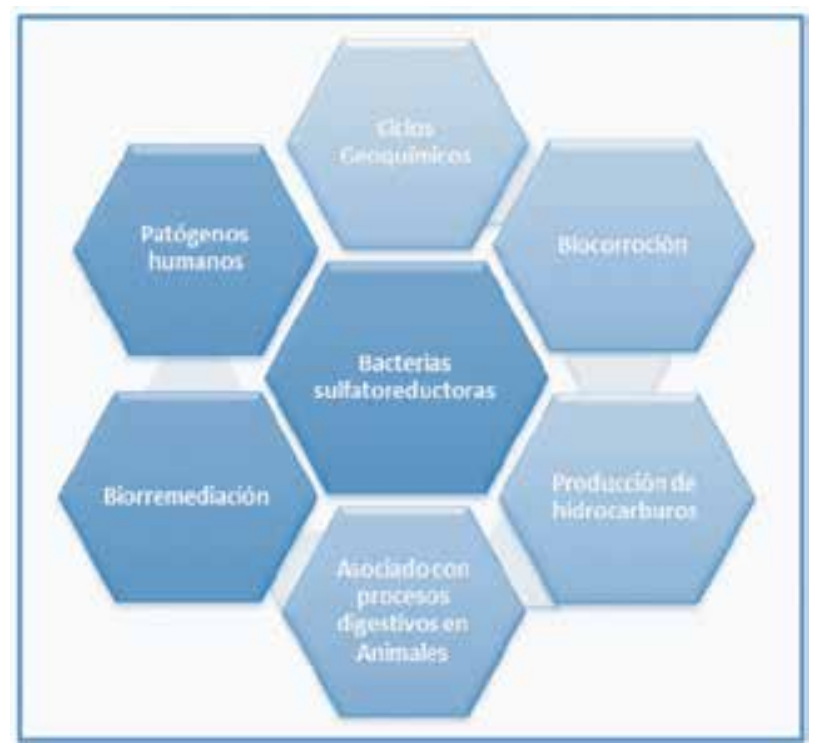

Figura 2. Vías de interacción de las bacterias Sulfatoreductoras. / Antolinez DM Modificado de Barton, 1995 (17).

\section{Fases de la digestión anaerobia Hidrólisis}

La hidrólisis es la descomposición biológica de polímeros orgánicos en moléculas más pequeñas (monómeros y dímeros) que son capaces de atravesar la membrana celular, este proceso se lleva a cabo por medio de enzimas denominadas hidrolasas, que son capaces de solubilizar la materia orgánica y romper enlaces específicos con ayuda de agua para poder ser utilizadas (18).

La degradación anaerobia principalmente se da en polímeros como celulosa y hemicelulosa, con la participación de enzimas celulasas. De esta enzima se conocen tres tipos: endocelulasa, encargadas de romper los enlaces $1,4-\beta$ glucosídicos internos del polímero para convertirlo en moléculas más pequeñas; exocelulasas encargadas de romper los enlaces 1,4- $\beta$ glucosídicos de los polímeros reducidos por las endocelulasas obteniendo tetrámeros o dímeros y por último, las celobiasas o $\beta$-glucosidasas las cuales hidrolizan las moléculas resultantes de la última hidrolisis en dos moléculas de glucosa (8).

Dentro de las bacterias anaerobias, que participan en las fases de hidrólisis y acidogénesis, se encuentran Peptostreptococcus, Propionibacterium, Bacteroides, Micrococcus y Clostridium que interactúan con algunas bacterias de la familia Enterobacteriaceae (19).

\section{Fermentación anaerobia}

La fermentación anaeróbica incluye un complejo número de microorganismos con diferentes características y capacidades, durante el proceso de producción del metabolito los productos finales son sustancias orgánicas, por ejemplo, ácido láctico, ácido propiónico, ácido acético, butanol, etanol y acetona. En los procesos anaerobios los microorganismos producen mucho menos energía que en los aerobios, y para suplir 
sus necesidades de energía metabolizan una mayor cantidad de azucares y por consiguiente elaboran una mayor cantidad de metabolitos. Estos microorganismos llevan a la producción de metano en la última etapa del proceso de digestión anaerobia. Las bacterias productoras del biogás son estrictamente anaeróbicas y por lo tanto sólo podrán sobrevivir en ausencia total de oxígeno atmosférico (20).

En esta etapa, principalmente, los productos de la hidrólisis son convertidos en ácidos orgánicos, y en la fermentación como paso siguiente a la hidrólisis el material orgánico soluble es transformado en acetato, ácidos grasos de cadena corta, alcoholes, hidrógeno y dióxido de carbono (8). Las bacterias anaerobias fermentativas utilizan rutas catabólicas de polisacáridos, aminoácidos y glicerol para la producción de glucosa, la cual puede ser utilizada en las rutas de fermentación alcohólica, láctica y acética. Como resultado de esta fermentación se obtienen alcoholes y ácidos grasos (21).

Entre los principales productos de la fermentación de carbohidratos se encuentran los ácidos grasos volátiles. Estos son importantes intermediarios para la producción de metano y su concentración es muy importante para la eficiencia de la metanogénesis (21).

Tabla 3. Tipo de fermentaciones y productos generados $(21,22,34)$

\section{Tipo de Fermentación}

Fermentación láctica

Fermentación alcohólica

Fermentación ácida-mixta

Fermentación butilénglicólica

Fermentación aceto-butírica

\section{Producto o productos}

Lactato
Etanol, $\mathrm{CO}_{2}$

Etanol, Succinato, Acetato, Formiato, Lactato, $\mathrm{CO}_{2}, \mathrm{H}_{2}$

Butilénglicol, $\mathrm{CO}_{2}$

\section{Procesos fermentativos}

A continuación se describen los diferentes tipos de fermentación en los que participan las bacterias.

\section{Fermentación alcohólica}

Es el tipo de fermentación más antigua que se conoce, es un proceso biológico que se lleva a cabo en ausencia de $\mathrm{O}_{2}$, originado por la actividad de algunos microorganismos. Produce etanol a partir de glucosa, aunque otras bacterias también producen alcohol, éste es elaborado por otras vías (23).
La fermentación alcohólica es un proceso biológico de fermentación en plena ausencia de aire (oxígeno $-\mathrm{O}_{2}$ ), originado por la actividad de algunos microorganismos que procesan los hidratos de carbono (por regla general azúcares de tipo hexosa: como por ejemplo la glucosa, la fructosa, la sacarosa para obtener como productos finales: un alcohol en forma de etanol cuya fórmula química es: $\left(\mathrm{CH}_{3}-\mathrm{CH}_{2}-\mathrm{OH}\right)$, dióxido de carbono $\left(\mathrm{CO}_{2}\right)$ en forma de gas y unas moléculas de ATP que consumen los propios microorganismos en su metabolismo celular energético anaeróbico (24). 
La reacción de fermentación se representa por la siguiente ecuación:

\section{$\mathrm{C}_{6} \mathrm{H}_{12} \mathrm{O}_{6} \longrightarrow 2 \mathrm{C}_{2} \mathrm{H}_{5} \mathrm{OH}+2 \mathrm{CO}_{2}$}

La fermentación alcohólica tiene como finalidad biológica proporcionar energía anaeróbica a partir de la glucosa a los microorganismos unicelulares (levaduras) en ausencia de oxígeno (24).

\section{Fermentación heteroláctica}

En esta fermentación, su producto final, no es exclusivamente el ácido láctico como lo es la fermentación homolactica, Figura 3. En este tipo de fermentación se pueden producir otros productos finales como ácido acético y ácido fórmico generados por bacterias del género Bifidobacterium (25). Las bifidobacterias son un grupo predominante de la microflora del colon que puede representar hasta el $25 \%$ del número total de bacterias presentes $(26,27)$. Debido a su naturaleza heterofermentativa, las bifidobacterias pueden producir ácido láctico y etanol, así como varios ácidos grasos de cadena corta tales como ácido acético y ácido fórmico. Algunos investigadores también han mencionado la producción de pequeñas cantidades de dióxido de carbono y ácido succínico por parte de estos microorganismos (28).

La reacción se representa por la siguiente ecuación:

Glucosa $+\mathrm{ADP}+\mathrm{P}_{\mathrm{i}} \longrightarrow$ Ac. Láctico + etanol $+\mathrm{CO}_{2}+\mathrm{ATP}$

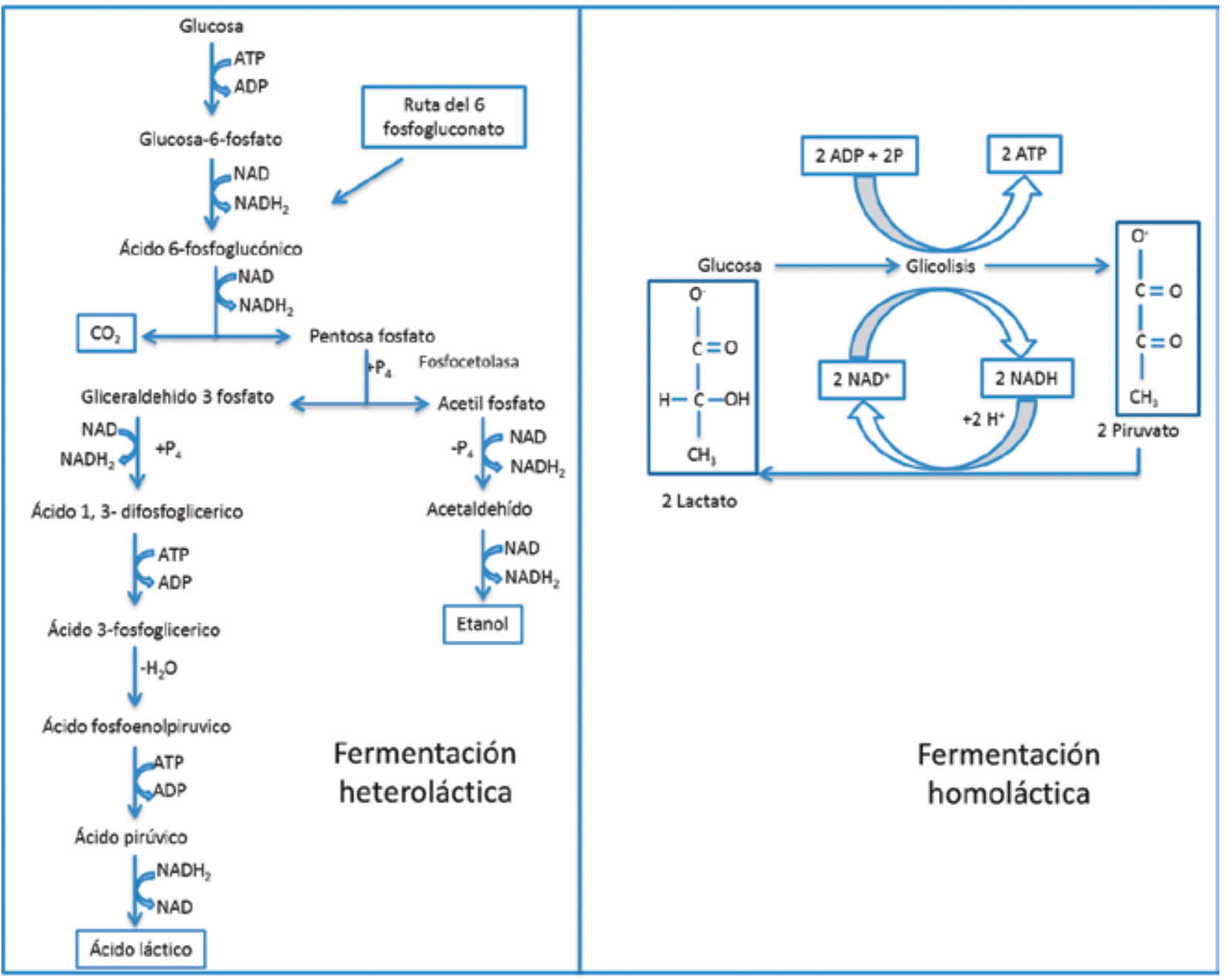

Figura 3. Fermentaciones lácticas. / Antolinez DM. Modificado de: Microbiología. Roger Y. Stanier. 2005 


\section{Fermentación acetona-butanol}

Es una variación de la fermentación ácido-mixta, Figura 4 en la que también se forman butanol, etanol, acetona e isopropanol, esta es una característica de algunas especies del género Clostridium (29). La ruta metabólica para la producción de acetona-butanol-etanol está dada en dos diferentes fases, pero que tienen ciertas características de la fermentación que son nombradas comúnmente como fases de acidogénesis y solventogénesis. La primera fase está comprendida por la formación de ácido acético, butírico y ATP durante el crecimiento exponencial de las células. A esta fase le sigue otra donde el crecimiento va a ser estacionario, es en esta parte del proceso en que la solventogénesis toma lugar, los ácidos son asimilados, y la acetona-butanoletanol aparece como metabolitos secundarios.

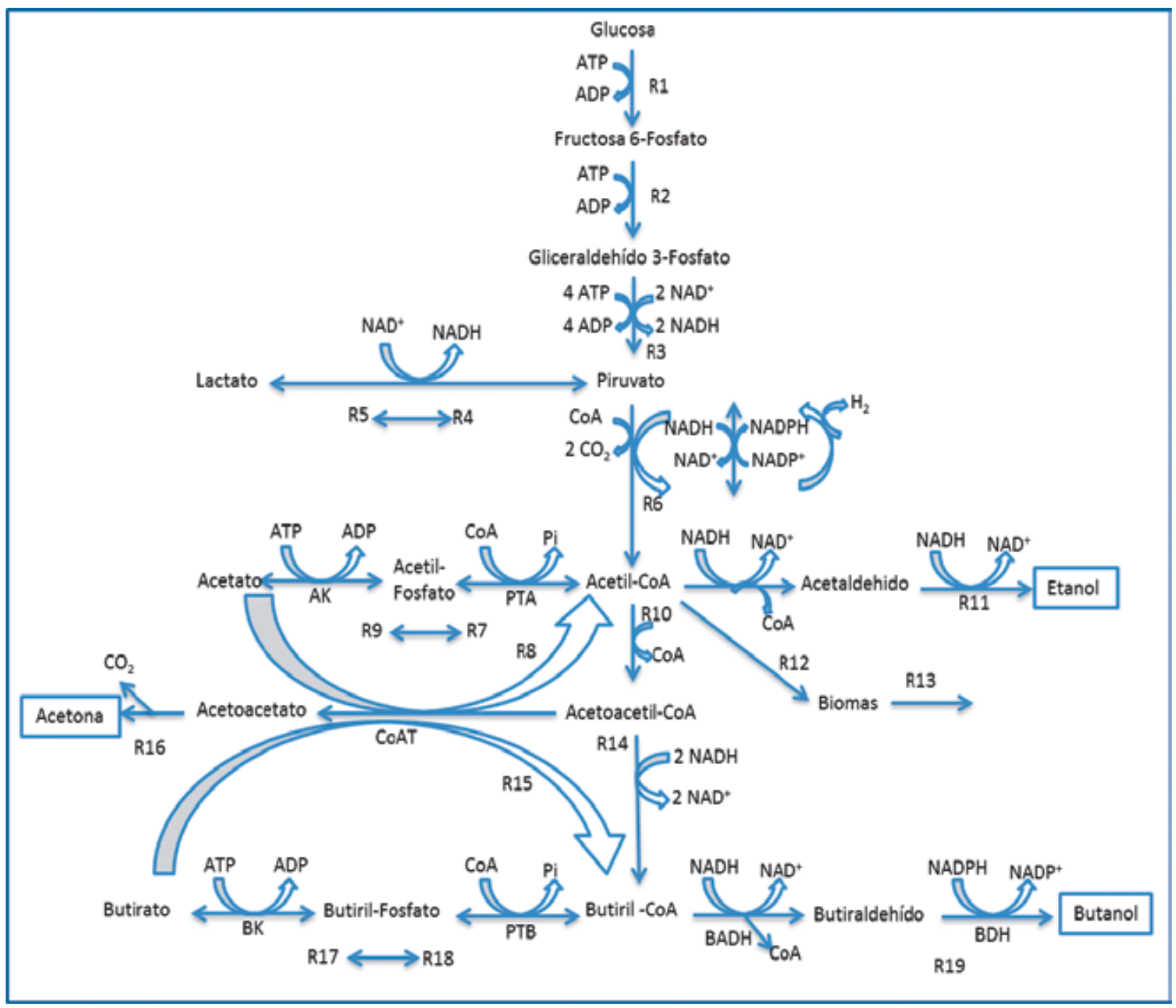

Figura 4. Fermentación acetona-butanol. / Antolinez DM

Las enzimas PTA: Fosfotransacetilasa; AK: Acetatokinasa; CoAT: CoA transferasa; PTB: Fosfotransbutirilasa; BK: Butirato kinasa; BADH: Butiraldehido deshidrogenasa; BDH: Butanol deshidrogenasa (30).Tomado de: Análisis de la producción de biobutanol en la fermentación acetobutilica con Clostridium saccharoperbutylacetonicum N1-4 ATCC13564. Ruta metabólica en Clostridium acetobutylicum. 2010. 


\section{Fermentación propiónica}

Los productos principales de este tipo de fermentación son ácido propiónico, ácido acético, ácido succínico y dióxido de carbono, como se muestra en la Figura 5. Es característica de las bacterias del género Propionibacterium, Veillonella y Clostridium propionicum, que pueden producir ácido propiónico utilizando el ácido láctico como sustrato, y algunas también a partir de polialcoholes, aminoácidos y otros ácidos orgánicos distintos al ácido láctico (31).

Los mecanismos de la fermentación propiónica de las hexosas se hace de dos maneras:
Hexosas $\rightarrow$ ácido láctico $\rightarrow$ ácido propiónico

Hexosas $\rightarrow$ ácido pirúvico $\rightarrow$ ácido propiónico (32).

Como ya se ha mencionado en este proceso fermentativo la mayoría de bacterias presentes son del género Propionibacterium, aunque también participan otras bacterias anaerobias estrictas, las cuales realizan principalmente fermentación secundaria de los productos de las fermentaciones lácticas primarias. Pueden fermentar la glucosa y glicerol para producir ácido propiónico y ácidos acético y succínico como dos subproductos $(33,34)$.

Su ecuación fundamental es la siguiente:

$3 \mathrm{C}_{6} \mathrm{H}_{12} \mathrm{O}_{6} \rightarrow 4 \mathrm{CH}_{3}-\mathrm{CH}_{2}-\mathrm{COOH}+2 \mathrm{CH}_{3}-\mathrm{COOH}+2 \mathrm{CO}_{2}+2 \mathrm{H}_{2} \mathrm{O}$

Glucosa $\rightarrow$ Ac. Propiónico + Ac. Acético $+\mathrm{CO}_{2}+3$ ATP

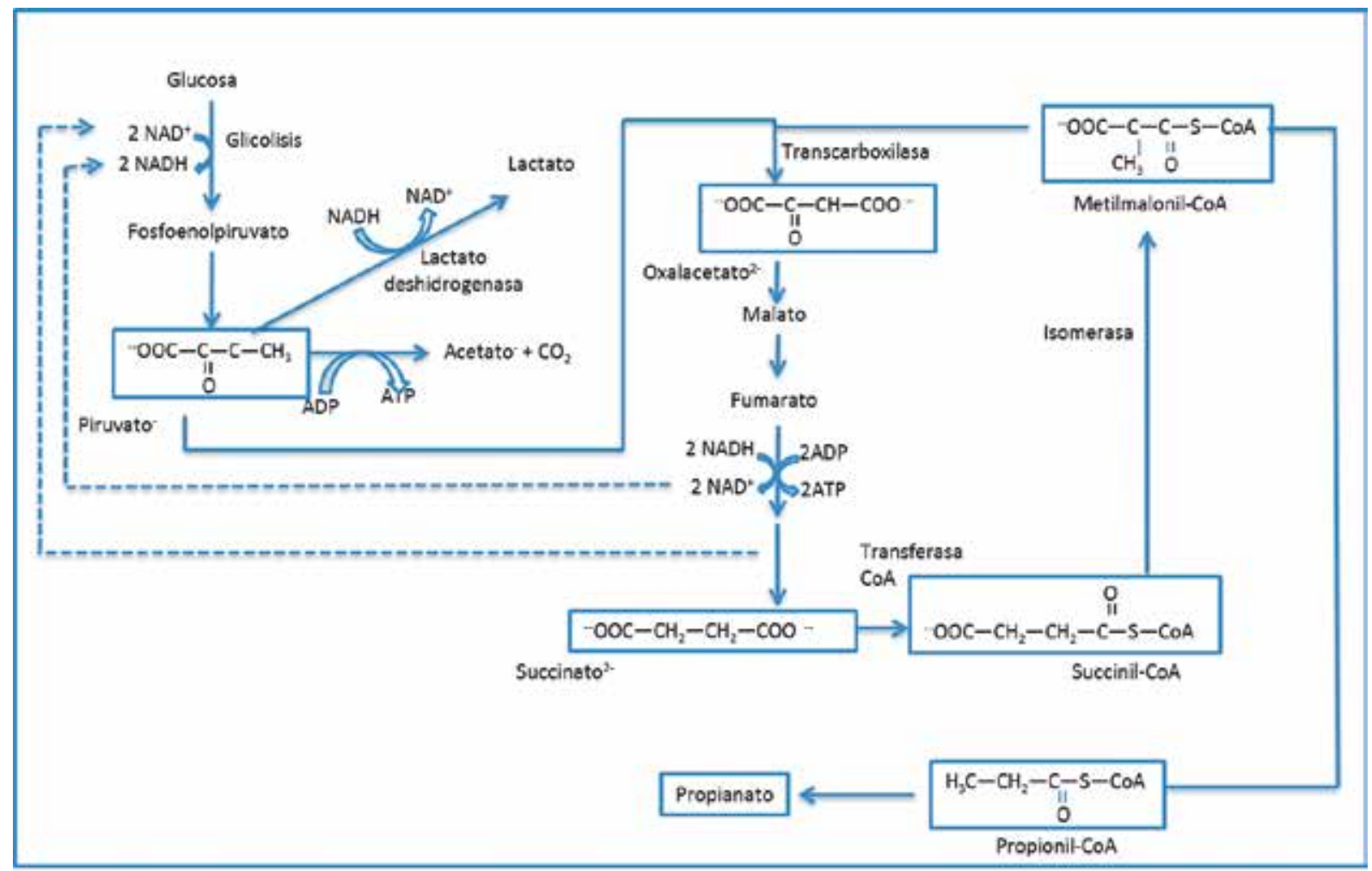

Figura 5. Fermentación propiónica, género Propionibacterium. / Antolinez DM. Modificado de: C Allison and G T Macfarlane. Dissimilatory nitrate reduction by Propionibacterium acnes. 1989 (34). 


\section{Fermentación del ácido butírico}

Se presenta generalmente en bacterias del género Clostridium. Si bien hasta ahora la referencia ha sido la fermentación de hidratos de carbono como procedimiento para obtener energía, se debe mencionar que otros compuestos orgánicos pueden ser fer- mentados, por ejemplo: aminoácidos (alanina, glicina) $(24,35)$. En la Figura 6 se muestra el proceso de la fermentación butírica y la obtención de los productos finales.

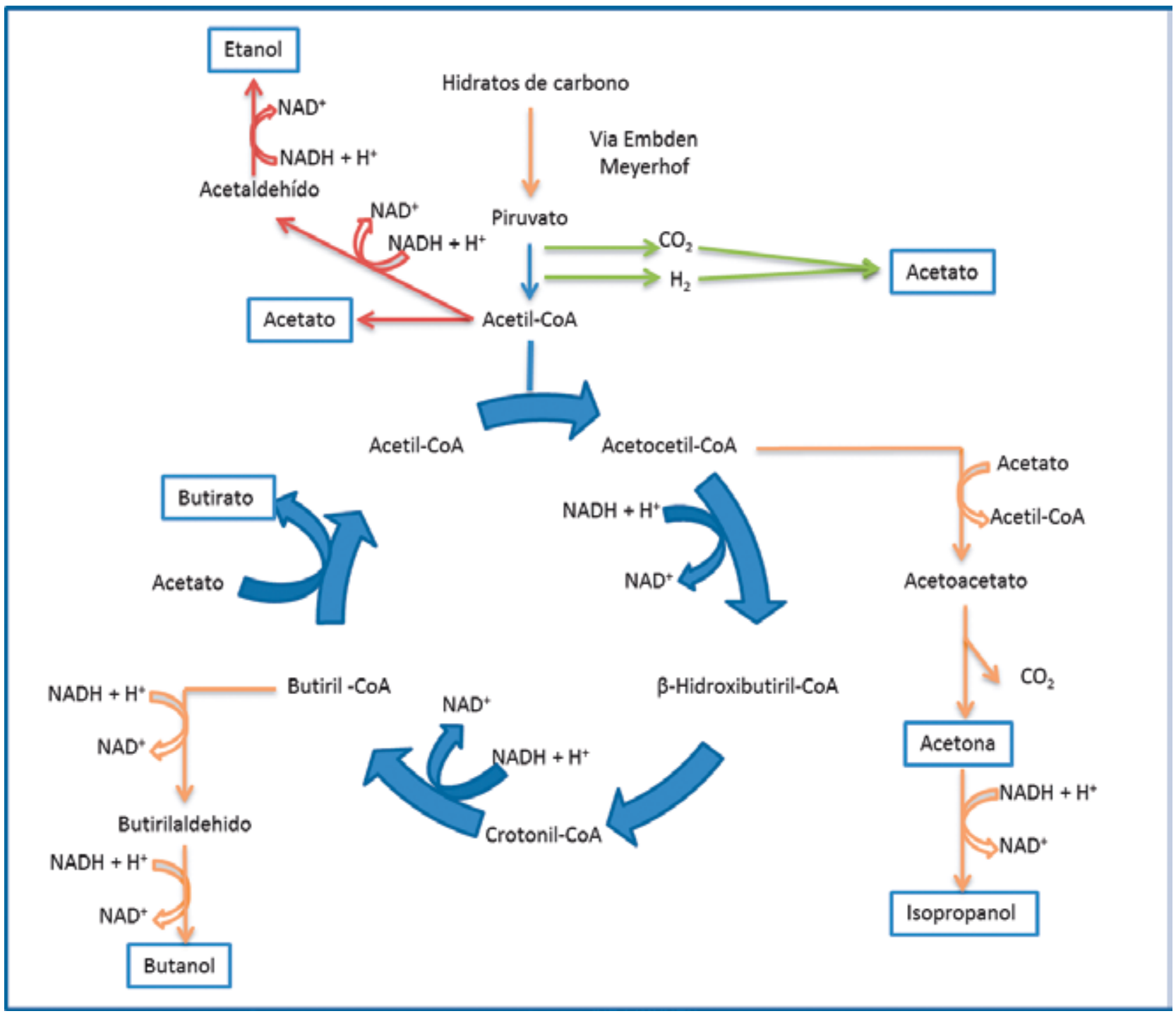

Figura 6. Formación de los productos finales de la fermentación de hidratos de carbono por las bacterias del ácido butírico. / Antolinez DM. Modificado de: bioquímica de los microorganismos. Ramón Parés. Antonio Juáres.2002. En color azul producción de butirato. En color rojo producción de acetato y etanol a partir del acetil-CoA. En color naranja producción de butanol acetona e isopropanol. En color verde producción de acetato a partir de $\mathrm{CO} 2$ e H2-. Los productos finales se muestran en los recuadros (35). 


\section{Acetogénesis}

Esta es una fase en la cual se aceleran los procesos metabólicos bacterianos, con transformación enzimática o hidrólisis, de lípidos, polisacáridos, proteínas y ácidos nucleicos, en otros compuestos que serán utilizados como fuentes de energía y como transformación a carbono celular (36).

En la acetogénesis, los ácidos grasos volátiles se convierten en ácido acético, dióxido de carbono e hidrógeno. El ácido acético es producido por dos diferentes mecanismos: acetogénesis por hidrogenación, en la cual se produce acetato ( $\left.\mathrm{CH}_{3} \mathrm{COO}-\right)$ como producto final de la reducción de dióxido de carbono $\left(\mathrm{CO}_{2}\right)$ más hidrogeno $(\mathrm{H})$ y la acetogénesis por deshidrogenación en donde las bacterias son inhibidas por pocas cantidades de oxígeno $\left(\mathrm{O}_{2}\right)$ y por lo tanto solo sobreviven en asociaciones con microorganismos que consumen hidrogeno como las bacterias homoacetogénicas (fermentación láctica) y bacterias sulfato reductoras.

Las bacterias homoacetogénicas son microorganismos anaerobios estrictos los cuales catalizan la formación de acetato a partir de hidrogeno $(\mathrm{H})$ y dióxido de carbono $\left(\mathrm{CO}_{2}\right)$. La reducción del dióxido de carbono en todos los homoacetógenos se produce por la ruta de la acetil-CoA, esta ruta también es útil para la fijación de carbono por las bacterias sulfatoreductoras y la fermentación de homoacetógenos para producir acetato como producto final (8).

Dentro de los géneros más sobresalientes de las bacterias homoacetogénicas se encuentran Clostridium aceticum, Clostridium formicoaceticum y Acetobacterium wooddi $(19,37,43)$.

\section{$2 \mathrm{CO}_{2}(\mathrm{aq})+4 \mathrm{H}_{2}(\mathrm{aq})$}

\section{$\mathrm{CH}_{3} \mathrm{COOH}(\mathrm{aq})+2 \mathrm{H}_{2} \mathrm{O}$}

\section{Metanogénesis}

La metanogénesis es la etapa final de la digestión anaerobia. La formación de metano se da a partir de dos rutas principales, la primera, es la acetoclástica en la cual los microorganismos crecen principalmente en su sustrato (acetato) y la segunda, es la hidrogenotrófica en donde los microorganismos crecen en sustratos como hidrógeno $(\mathrm{H})$ y dióxido de carbono $\left(\mathrm{CO}_{2}\right)$. Su metabolismo se caracteriza por integrar las vías biosintéticas y bioenergéticas para la producción de ATP, además en ausencia de hidrógeno, oxidan compuestos para la obtención de electrones (35).

\section{$\mathrm{CH}_{3} \mathrm{COO}^{-}+\mathrm{H} \longrightarrow \mathrm{CH}_{4}+\mathrm{CO}_{2}$ acetoclástica}

\section{$4 \mathrm{H}_{2}+\mathrm{CO}_{2} \longrightarrow \mathrm{CO}_{4}+\mathrm{H}_{2} \mathrm{O}$ hidrogenotrófica}

El producto final es el metano $\left(\mathrm{CH}_{4}\right)$ y el aporte de la vía hidrogenotrófica es del 27 al $30 \%$ y por la vía acetoclástica es del $70 \%(39)$. 
Por otro lado, las bacterias metanogénicas pueden ser consideradas como las más importantes dentro del consorcio de microorganismos anaerobios ya que tienen la capacidad de producir gas metano $\left(\mathrm{CH}_{4}\right)$ a través de la conversión de substratos monocarbonados o con átomos de carbono unidos por un enlace covalente como el acetato, $\mathrm{H}_{2}, \mathrm{CO}_{2}$, formato, metanol y algunas metilaminas, Figura 7. (40).
Existen otras formas que permiten la metanogénesis, esto depende de los sustratos que se utilicen o se encuentren en el ambiente, puede ser a partir de ácidos orgánicos, alcoholes y pequeñas moléculas que son utilizadas por los anaerobios estrictos, así como el metano puede ser el sustrato de diferentes microorganismos entre ellos los aerobios estrictos $(41,42)$.

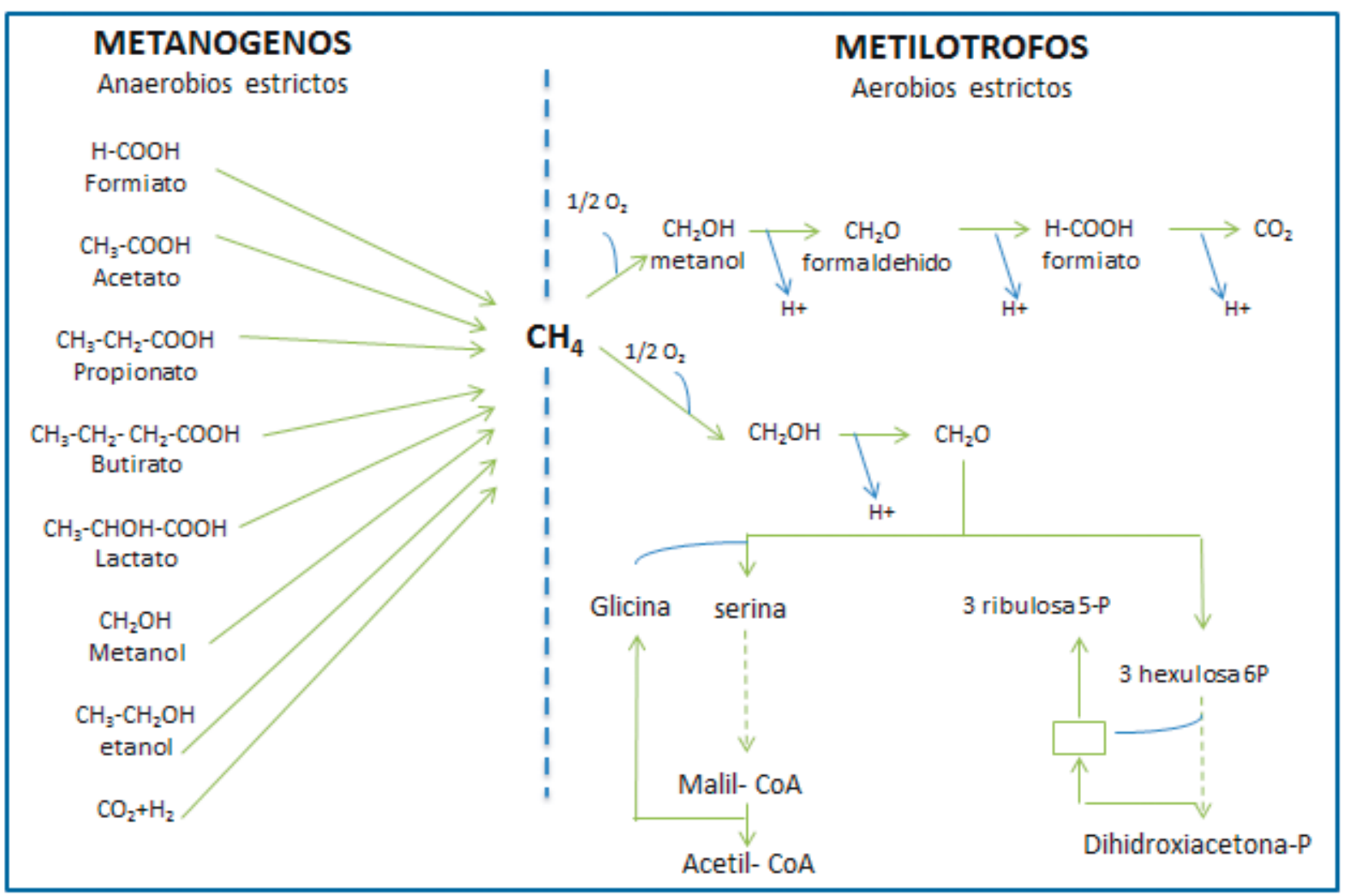

Figura 7. Metabolismo microbiano del metano. / J.A.Bohórquez (42). Modificado de: bioquímica de los microorganismos. Ramón Parés. Antonio Juáres.2002

En la figura 7, se observa la oxidación de $\mathrm{CO}_{2}$ en color azul, mientras que la formación de esqueletos carbonados tiene lugar asimilando el formaldehido, que puede ser por la vía de la serina (izquierda) o bien por el ciclo de la rubilosa monofosfato (derecha). En esta vía se observan reacciones catalizadas por aldosas y trancetolasas (42).

El análisis del ARNr 16S ha permitido identificar aproximadamente unas 90 especies de metanógenas distribuidas en 5 clases distintas: Methanobacteria,
Methanococci, Methanomicrobiota, Methanopyri y Methanosarcinales. Estas bacterias abundan en ambientes donde se encuentran aceptores de electrones tales como $\mathrm{O}_{2}, \mathrm{NO}^{3-}, \mathrm{Fe}^{3+}, \mathrm{y} \mathrm{SO}_{4}^{2-}$. Se encuentran en hábitats típicos como digestores anaerobios, sedimentos anóxicos, suelos de humedales y tractos gastrointestinales (42).

Los organismos metanogénicos se clasifican dentro del dominio Archaea, y, morfológicamente, pueden ser bacilos cortos y largos, cocos con diferentes 
asociaciones celulares, células en forma de placas y metanógenos filamentosos, existiendo tanto Gram positivos como Gram negativos dependiendo del sustrato sobre el que crecen, se pueden dividir en tres clases principales: los que usan un sustrato de tipo $\mathrm{CO}_{2}$; las que utilizan un sustrato de tipo metilo ó un sustrato de tipo acetato, a partir de los cuales obtienen energía por medio del proceso denominado metanogénesis (43).

En el primer paso de este proceso, suponiendo que se usa un sustrato $\mathrm{CO}_{2}$, interviene una coenzima llamada metanofurano que realiza la reducción del $\mathrm{CO}_{2}$ a formilo. En el siguiente paso la metanopterina se une al $\mathrm{C} 1$ de dicho formilo y lleva a la futura molécula de metano desde su estado de formilo hasta metilo, realizándose en el proceso una serie de reducciones por la coenzima F420, quien transporta electrones obtenidos del $\mathrm{H}_{2}$ para producir dicha reducción a metilo (8).

Después es la coenzima $\mathrm{M}$ quien interviene sobre el grupo metilo, el cual es reducido a metano, en el último paso de la metanogénesis, con la intervención del complejo enzimático reductasa metil-F430 y la coenzima B. Este proceso es enlazado con la síntesis de compuestos orgánicos por medio de un corrinoide al que la metanopterina cede el grupo metilo en lugar de hacerlo a la coenzima $\mathrm{M}$, por lo que la bacteria ahorra en enzimas, rutas y energía. La reacción de producción de metano es fuertemente exoenergética, y la emplean como fuente de energía $(44,45)$.

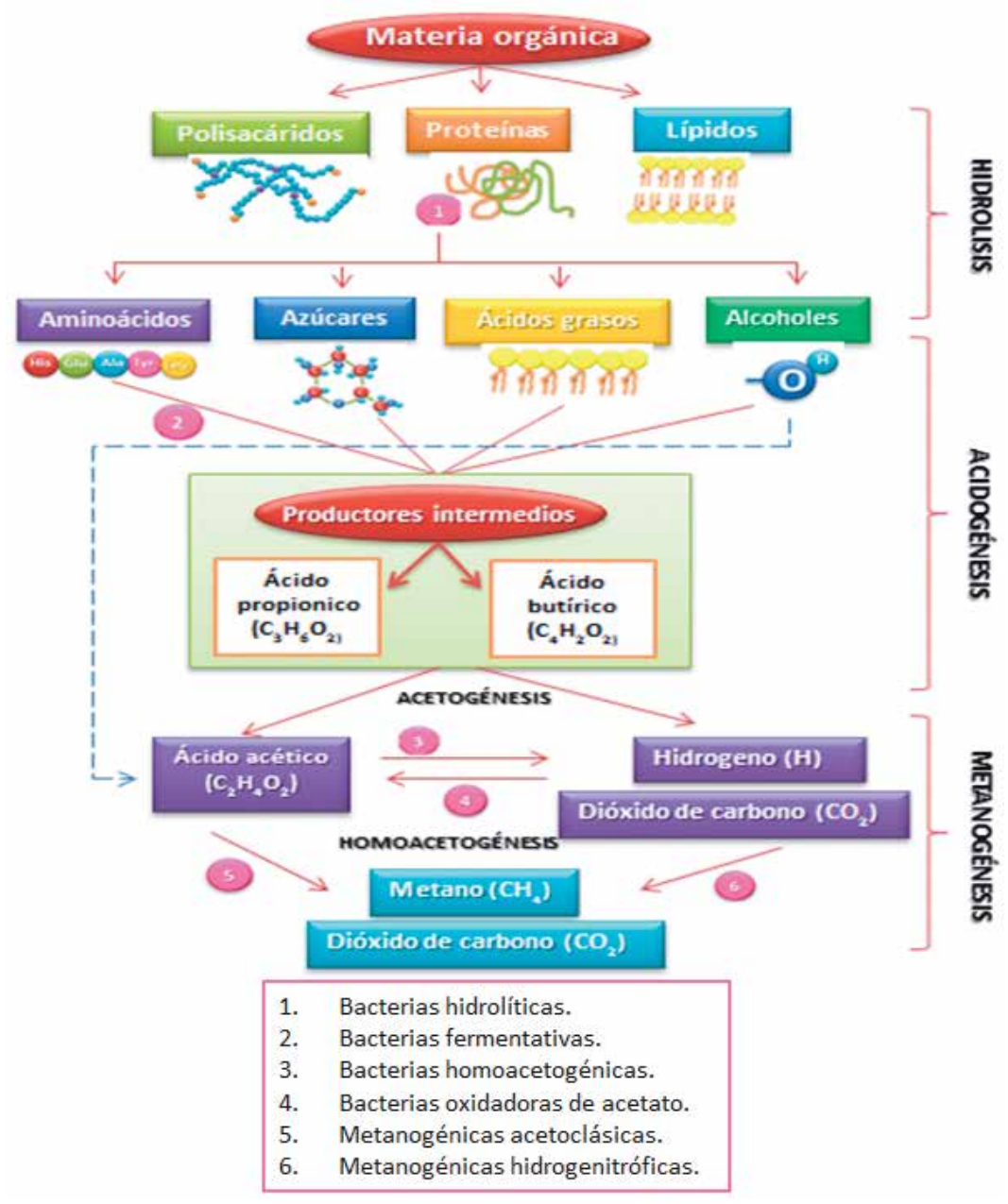

Figura 8. Proceso de la digestión anaerobia. / Bohórquez JA, Corredor AM. Modificado de Pavlostathis y Giraldo-Gómez. 1991 (45). 
En la Figura 8, se muestran varios microorganismos anaerobios estrictos y algunos facultativos que participan en cada uno de los procesos de las diferentes fases de la digestión anaerobia.

- Fase no metanogénica: Bacteroides sp, Clostridium sp, Bifidobacterium sp, Sphaerophorus sp, Fusobacteium sp, Veillonella $s p$, Peptococcus $s p$, Desulfovibrio sp. y otros como: Lactobacillus $s p$, Actinomyces sp, Corynebacterium sp, Micrococcus sp, Spirillum sp, Sarcina sp (10).

- Fase metanogénica: Bacteroides sp, Clostridium sp, Bifidobacterium sp, Sphaerophorus sp, Fusobacteium sp, Veillonella sp, Peptococcus sp, Desulfovibrio sp. y otros como: Methanobacterium sp, Methanococcus sp, Methanospirillum sp, Methanobrevibacter sp, Methanomicrobium sp (46).

\section{Bacterias sintróficas}

Dentro del metabolismo de la digestión anaerobia existen grupos de bacterias sintróficas cuya principal característica es la unión de varias especies para realizar una reacción química. Existen $4 \mathrm{ca}$ tegorías de bacterias que participan en los pasos de conversión de la materia hasta moléculas sencillas como metano o dióxido de carbono y que van cooperando de forma sinérgica, estas son:

Grupo 1: Bacterias hidrolíticas. Son un conjunto de bacterias cuya finalidad es romper los enlaces complejos de proteínas, celulosa, lignina o lípidos en monómeros o moléculas como aminoácidos, glucosa, ácidos grasos y glicerol, los cuales pasan al siguiente grupo de bacterias. En este proceso participan principalmente Clostridium y Bacteroides (47).

Grupo 2: Bacterias fermentativas acidogénicas. Las cuales se encargan de convertir azúcares, aminoácidos y lípidos en ácidos orgánicos, alcoholes y cetonas, acetato, $\mathrm{CO}_{2} \mathrm{y} \mathrm{H}_{2}$, siendo Clostridium el microorganismo que se encuentra principalmente realizando este proceso, aunque Lactobacillus y Bacillus, también lo hacen (47).

Grupo 3: Bacterias acetogénicas. Estas solo se desarrollan como productoras de $\mathrm{H}_{2}$ junto a otras bacterias consumidoras de este. Syntrophobacter wolinii, especializada en la oxidación de propionato, y Syntrophomonas wolfei, que oxida ácidos grasos de 4 a 8 átomos de carbono, convierten el propiónico, butírico y algunos alcoholes en acetato, hidrógeno y dióxido de carbono, el cual se utiliza en la metanogénesis (47).

Grupo 4: Bacterias metanógenicas: son aquellas bacterias capaces de generar gas metano como última fase de la digestión anaerobia descrita anteriormente $(45,47)$.

A continuación se establecen otros procesos metabólicos en los que participan las bacterias.

\section{Metabolismo del nitrógeno}

Los microorganismos actúan sobre el nitrógeno mediante las proteinasas y peptidasas, las cuales hidrolizan las proteínas a péptidos y aminoácidos libres; los aminoácidos libres son utilizados directamente para la síntesis de proteínas y constituyentes celulares como la pared celular y ácidos nucleicos; los aminoácidos son también catalizados a ácidos grasos volátiles, otros ácidos, $\mathrm{CO}_{2} \mathrm{y}$ amoníaco; la urea es hidrolizada a amoníaco por acción de la ureasa; los nitratos son reducidos a amoníaco y el amoníaco se utiliza en la síntesis de los componentes celulares microbianos como las proteínas, entre otros (48).

Todas las bacterias no tienen la misma capacidad para degradar por la vía anaerobia proteínas, peptonas, polipéptidos y aminoácidos. Las que tienen esta propiedad se denominan bacterias putrefactivas porque a menudo generan productos de olor desagradable. Las bacterias putrefactivas son las que pueden llevar a cabo la degradación catabólica de compuestos nitrogenados en condiciones 
anaeróbicas y con frecuencia, las sustancias resultado del proceso pueden suministrar el carbono y el nitrógeno necesarios para su desarrollo (48).

Las bacterias putrefactivas son sobre todo especies del género Clostridium, como C. botulinum, $C$. perfringens, C. sporongenes, C. tetani y C. tetanomorphum. Además de éste género encontramos otras especies putrefactivas pertenecientes a grupos taxonómicos distintos, como la de los géneros Fusobacterium, Streptococcus, Micrococcus y Proteus (48).

Las bacterias putrefactivas son alcalófilas y a su vez tienden a alcalinizar los medios de cultivo, debido a que se libera amoniaco con formación de ácidos débiles, o se liberan bases orgánicas. Es conocido el hecho de que los organismos fermentadores y los putrefactivos son antagónicos y que, una vez que se ha desarrollado uno de ellos en un medio, difícilmente puede desarrollarse el otro (49).

Las macromoléculas proteicas no pueden penetrar dentro de la célula bacteriana, por esto muchas de ellas se liberan al medio, donde enzimas que las hidrolizan las transforman en aminoácidos o en péptidos de bajo peso molecular, con mayor facilidad para ingresar. Estas enzimas proteolíticas son endopeptidasas y exopeptidasas; las primeras rompen la cadena polipeptídica en cualquier punto con una misma probabilidad, mientras que la segunda sólo lo hace por los extremos. Las exopeptidasas se subdividen en aminopeptidasas, que requieren un grupo amino terminal y son dependientes de un ion metálico para su actividad, y las carboxipeptidasas, que hidrolizan péptidos con un carboxilo terminal. Los aminoácidos y otros compuestos heterocíclicos producto de la hidrólisis de sustancias nitrogenadas más complejas, se consideran los verdaderos sustratos del catabolismo fermentativo de los microorganismos putrefactivos (49).

\section{Fijación del nitrógeno}

El nitrógeno es un elemento necesario en la composición de proteínas, ácidos nucleicos y otros componentes celulares, siendo así una molécula esencial para el crecimiento de todos los organismos. Aunque es extremadamente común (80\% por volumen) en la atmósfera en forma de gas $\left(\mathrm{N}_{2}\right)$ es generalmente inaccesible biológicamente debido a su alta energía de activación. Aproximadamente el $78 \%$ de atmósfera está formado por $\mathrm{N}_{2}$, sin embargo, el nitrógeno atmosférico representa sólo el $1.2 \%$ del nitrógeno que hay sobre el planeta. Se debe tener en cuenta que el nitrógeno lo podemos encontrar presente en rocas y minerales, que representan un $98 \%$ aproximadamente del total del nitrógeno que hay en la Tierra (50).

El proceso por el cual los microorganismos reducen el nitrógeno hasta una forma utilizable se conoce como fijación biológica del nitrógeno (FBN) Figura 9. La reducción del nitrógeno atmosférico es un proceso bastante complejo porque requiere un gran aporte de energía para reducirse. El nitrógeno está compuesto por dos átomos de nitrógeno, los cuales están unidos por un triple enlace covalente, con lo que la molécula se vuelve altamente inerte y no reactiva. Los organismos responsables de la fijación de nitrógeno contienen la enzima nitrogenasa y se llaman diazótrofos. La nitrogenasa cataliza la ruptura de esta unión y adiciona tres átomos de hidrógeno a cada átomo de nitrógeno. Los microorganismos que fijan el nitrógeno requieren 16 moles de adenosin trifosfato (ATP) para reducir cada mol de nitrógeno (51).

En toda la naturaleza, solamente las bacterias especializadas son capaces de realizar la fijación de nitrógeno, convirtiéndolo en amoniaco $\left(\mathrm{NH}_{3}\right)$ que es asimilado fácilmente por todos los organismos. Estas bacterias, por lo tanto, son muy importantes ecológicamente y son a menudo esenciales para la supervivencia de ecosistemas grandes. Esto es especialmente cierto en el océano, en donde las Cyanobacterias fijadoras de nitrógeno son a menudo las únicas fuentes de nitrógeno. También es muy importante en el suelo, existiendo simbiosis especializadas entre legumbres y bacterias fijadoras de nitrógeno, imprescindibles para el crecimiento de estas plantas (52). 
La fijación de nitrógeno se puede encontrar en varios géneros bacterianos y en otros microorganismos pero no es universal, depende del tipo de microorganismo, el ambiente en el cual se desarrolla y las condiciones para el mismo, además de la presencia de enzimas que les ayudan en los diferentes procesos metabólicos que suceden para llegar finalmente a la fijación. La enzima nitrogenasa, responsable de la fijación de nitrógeno, es muy sensible al oxígeno, por lo que un pequeño contacto con este la inhibirá irreversiblemente, por esto los organismos fijadores de nitrógeno deben contar con mecanismos que le permitan mantener la concentración de oxigeno baja (52).

Los mecanismos utilizados son:

- Heterocistos (célula especializada en la fijación de nitrógeno atmosférico) en los agregados o filamentos celulares en bacterias del género como Cyanobacteria (por ejemplo Anabaena) en donde una célula no realiza la fotosíntesis sino que solamente fija el nitrógeno para sus socias que a cambio la proveen de energía.

- Nódulos en las raíces de las plantas (por ejemplo, Rhizobium), en donde la planta le proporciona oxígeno a la bacteria a través de moléculas de hemoglobina (53).

- Forma de vida anaerobia (por ejemplo, Clostridium pasteurianum).

- Metabolismo muy rápido (por ejemplo, Azotobacter vinelandii) (54).

La producción y actividad de la nitrogenasa se regula muy en detalle, tanto porque la fijación del nitrógeno es un proceso costoso energéticamente (ya que se requieren 16 a 24 ATPs por $\mathrm{N}_{2}$ fijado) como por la sensibilidad extrema de la nitrogenasa al oxígeno (55).

Los microorganismos se han adaptado y han tomado diferentes estrategias para evitar la inactivación de las nitrogenasas. Los mecanismos empleados para integrar la fijación biológica del nitrógeno (FBN) a los requerimientos fisiológicos son diversos y específicos, entre ellos se pueden destacar la evasión del $\mathrm{O}_{2}$ y el desarrollo en ambientes anaeróbicos, la generación de barreras físicas de protección que impidan la difusión del $\mathrm{O}_{2}$ y la eliminación metabólica del $\mathrm{O}_{2}$ para reducir su concentración a niveles aceptables e inocuos cerca de los complejos enzimáticos (55).

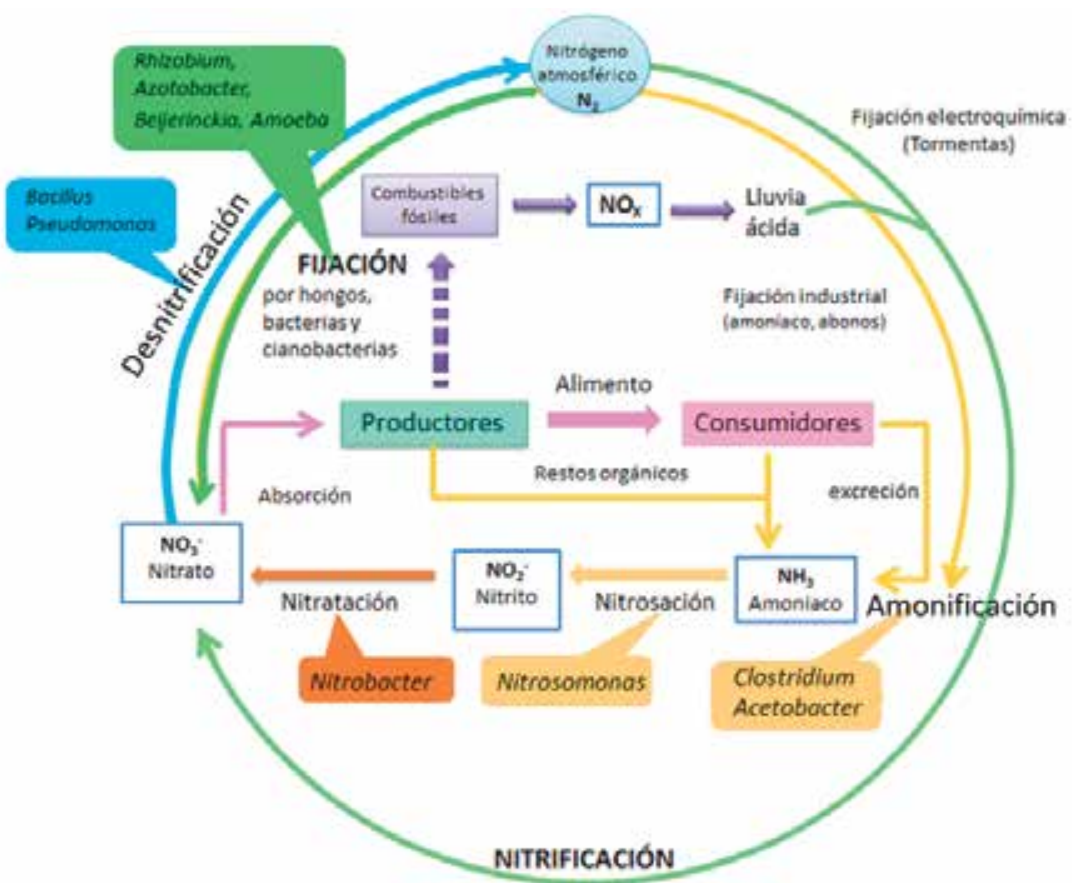

Figura 9. Ciclo del Nitrógeno. / Corredor A.M Modificado de: (Barea, J.M. Cuantificación de la fijación biológica de $N$ mediante el uso de N15. 1997) 
Las principales bacterias anaerobias asociadas a este proceso pertenecen a los géneros Thiobacillus, Clostridium, Desulfovibrio, Desulfotomaculum y Methanobacillus y otros anaerobios asociativos como: Agrobacterium, Azospirillum, Azotobacter, Bacillus y Beijerinckia (56).

\section{Oxidación del hierro ferroso}

En condiciones anoxigénicas el hierro ferroso puede ser oxidado por bacterias autótrofas anaerobias, $y$ en este caso el hierro es utilizado como donador de electrones para el crecimiento. En ausencia de oxígeno $\mathrm{el} \mathrm{Fe}^{2+}$ es estable a $\mathrm{pH}$ neutro, al cual se lleva a cabo la fotosíntesis anoxigénica. El descubrimiento de bacterias fotótrofas oxidadoras de $\mathrm{Fe}^{2+}$, permite explicar la evolución de la fotosíntesis y de los grandes depósitos de hierro férrico que están presentes en sedimentos desde hace mucho tiempo, pues parece probable que el ión férrico se formara mediante fotótrofos anoxigénicos que oxidaron el $\mathrm{Fe}^{2+}$ en ambientes anóxicos $(43,49,57)$.

\section{Deshidrogenación}

La glutamato deshidrogenasa y la alanina deshidrogenasa son enzimas ligadas al NAD+o al NADP+ que convierten al respectivo sustrato en ácido a-cetoglutárico y pirúvico donde se libera $\mathrm{NH}_{3}$. Para esta reacción el oxígeno no es esencial, Figura10.

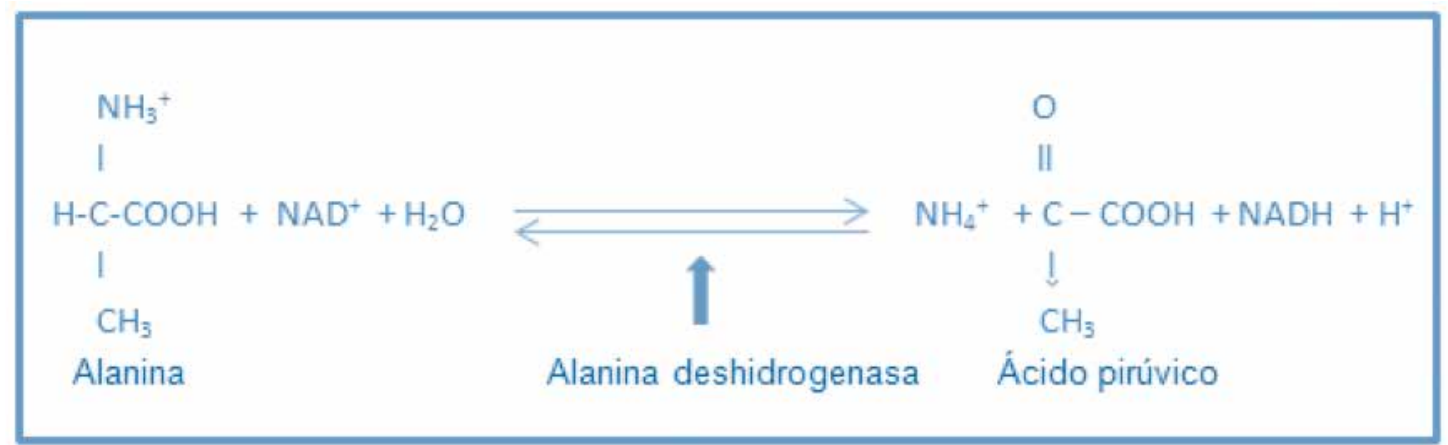

Figura 10. Reacción química del proceso de degradación oxidativa de deshidrogenasas. Modificado de: Metabolismo de compuestos nitrogenados. www.unac.edu.peldocumentos/.../CAPITULO\%20No\%2006.pdf

Las bacterias pueden desaminar los aminoácidos de distintas formas. La desaminación por instauración, tiene como producto final un ácido graso insaturado.

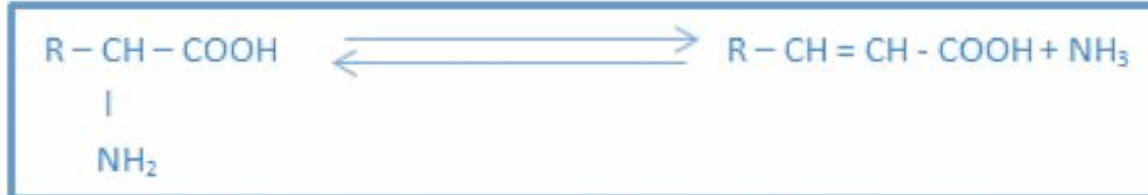

Figura 11. Reacción química de la desaminación de un aminoácido.

Modificado de: Metabolismo de compuestos nitrogenados. www.unac.edu.peldocumentos/.../CAPI-

TULO\%20No\%2006.pdf

Normalmente las bacterias anaerobias y facultativas que tienen deshidrogenasas, cuando actúan en ambientes anaerobios, realizan desaminación reductora y pueden utilizar el hidrógeno molecular como reductor. 


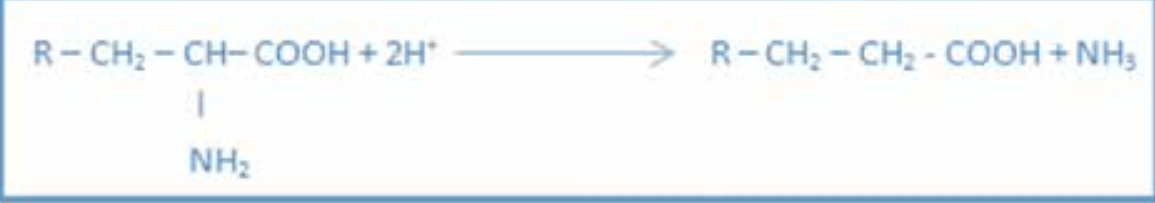

Figura 12. Reacción química desaminación reductora. Modificado de: Metabolismo de compuestos nitrogenados. www.unac.edu.peldocumentos/.../CAPITULO\%20No\%2006.pdf

El compuesto que se obtiene de la desaminación puede ser oxidado por vía anaerobia, para este proceso se necesita un aceptor de electrones estable, el cual puede proveerse libremente, como en la fermentación acoplada de aminoácidos, o puede resultar de la propia degradación metabólica del ácido orgánico. Por ejemplo, en el caso de Clostridium tetanomorphum este hidrógeno da lugar a una desaminación reductora, Figura 12.
En general, la fermentación de aminoácidos produce ácidos orgánicos, $\mathrm{CO}_{2}, \mathrm{H}_{2}$ y $\mathrm{NH}_{3}(58)$.

La L-arginina es desaminada en primera instancia por la arginina-desaminasa que la convierte en citrulina y luego la ornitina-carbamoil-transferasa mediante fosfato inorgánico la convierte en ornitina y carbamoil fosfato, Figura 13 (58).

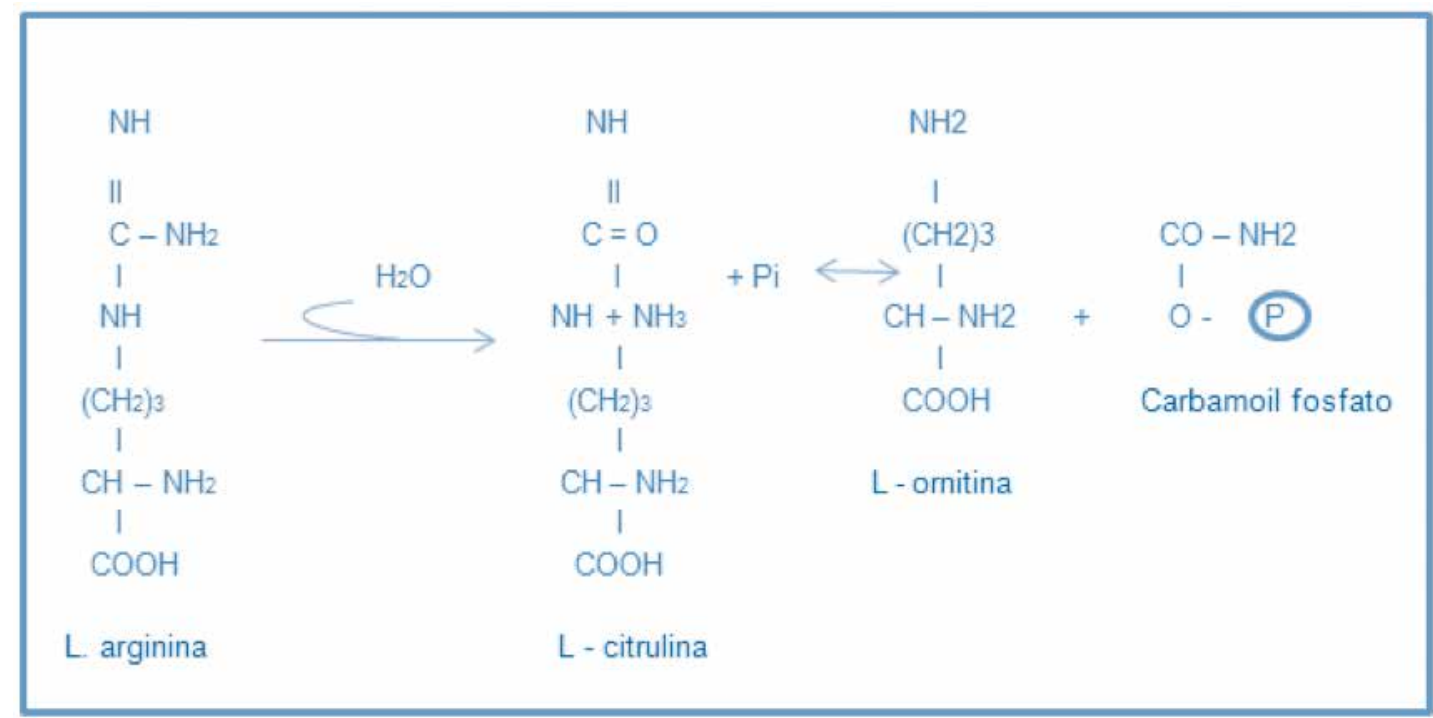

Figura 13. Proceso de desaminación de la L-arginina

Modificado de: Bioquímica Peña Antonio, Arroyo Ángel, Gómez Armando, Tapia Ricardo. 2004. (58).

El triptófano es fermentado lentamente por Clostridium sporogenes con la formación de ácido indol propionico; Clostridium propionicum lleva a cabo desaminación de la treonina a acetobutírico por una treonina-deshidratasa; Clostridium pasteurianum utiliza una serina hidroximetiltransferasa, con lo que rompe la treonina en glicina y acetaldehído, este último es reducido a etanol con reoxidación de NAD+.

\section{Procesos metabólicos con aminoácidos}

\section{Oxidación de la Lisina}

Clostridium sticklandii y otros clostridios utilizan la lisina como única fuente de carbono en condiciones anaerobias, en la cual se requiere la coenzima B12 como cofactor, y se suceden una serie de reacciones hasta la obtención de ácido butírico y acetato Figura 14, estas reacciones hacen parte de procesos oxido-reducción. 


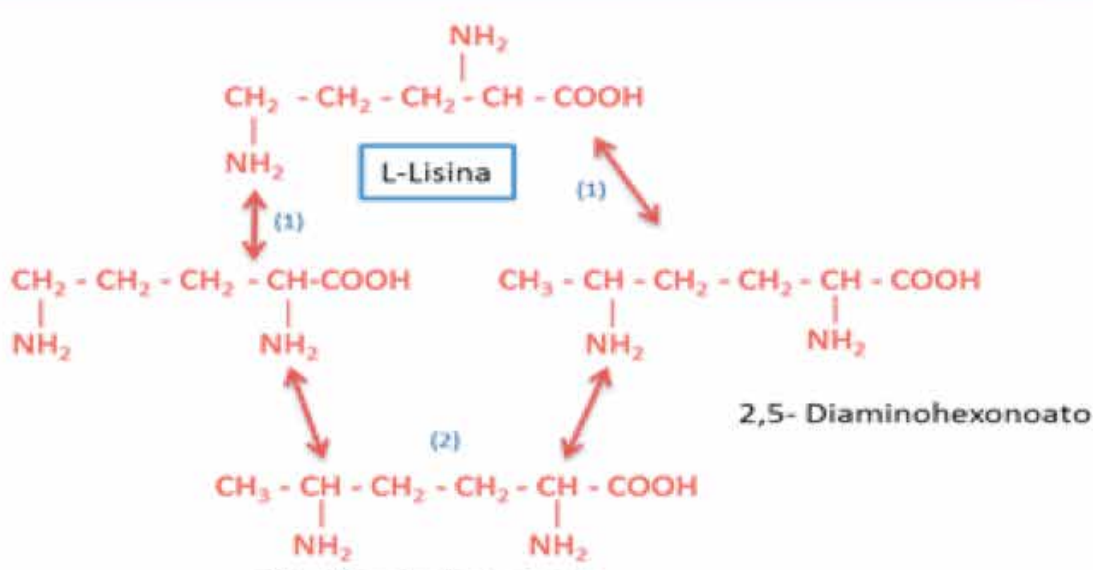

3,5- Diaminohexonoato

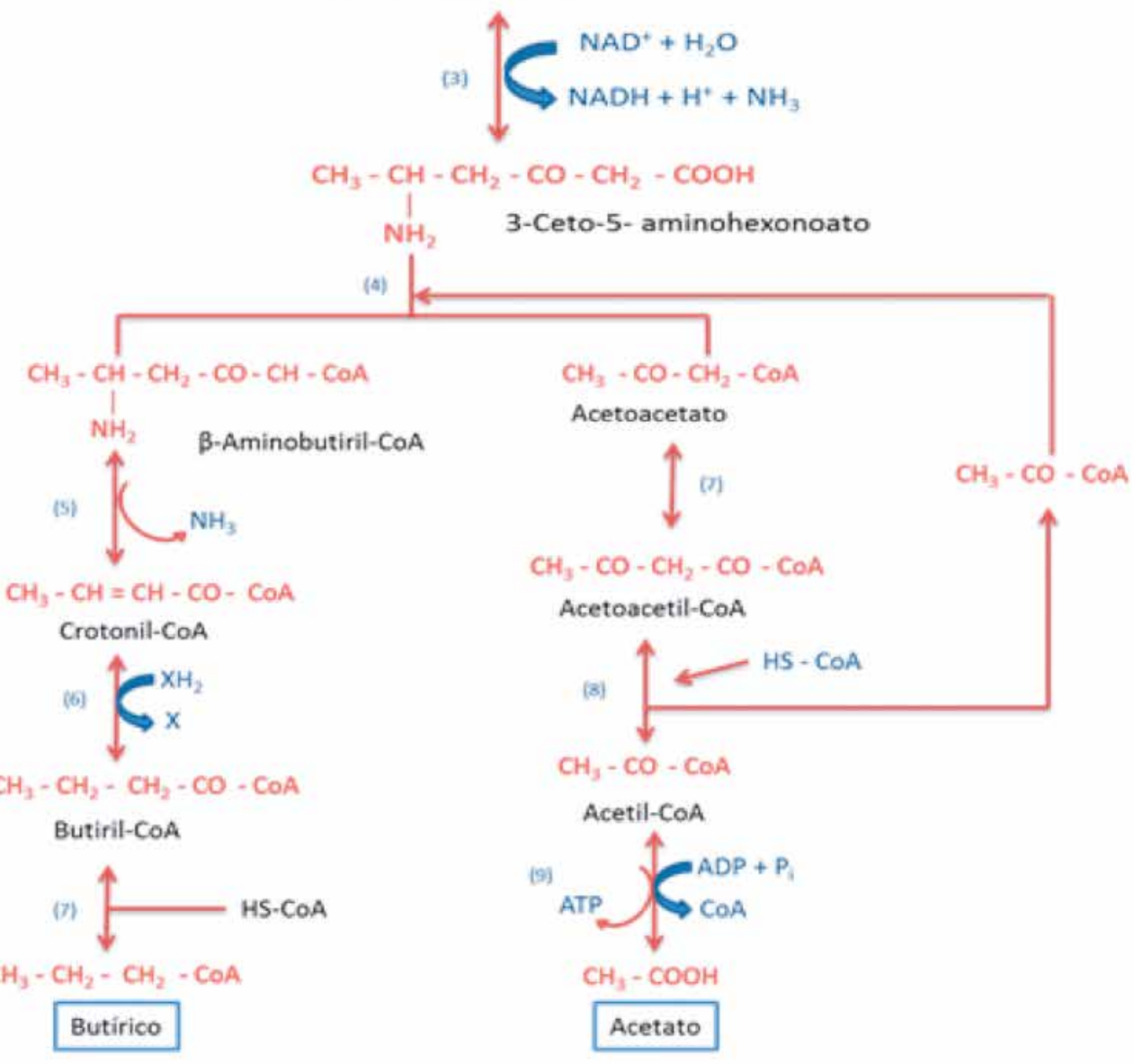

Figura 14. Oxidación de la Lisina./ Antolinez DM Tomado de: Christopher K. Mathews, Kensal E. van Holde, Dean R. Appling. Biochemistry 2012. (59). (1) L-Lisina, 2,3-aminomutasa. (2) $\beta$-lisina mutasa. (3) 3,5-Diaminohexanoato deshidrogenasa. (4) Enzima que hidroliza el 3-ceto-5-aminohexanoato. (5) Desaminasa. (6) Butiril-CoA deshidrogenasa. (7) CoAtransferasa. (8) $\beta$-cetotiolasa. (9)Fosfocetolasa acetato quinasa.

\section{Oxidación de la Ornitina}

Clostridium sticklandii fermenta la ornitina por una vía parecida a la de la lisina, con la diferencia de que además de la formación de acetato hay un producto final, la alanina, Figura 15. 


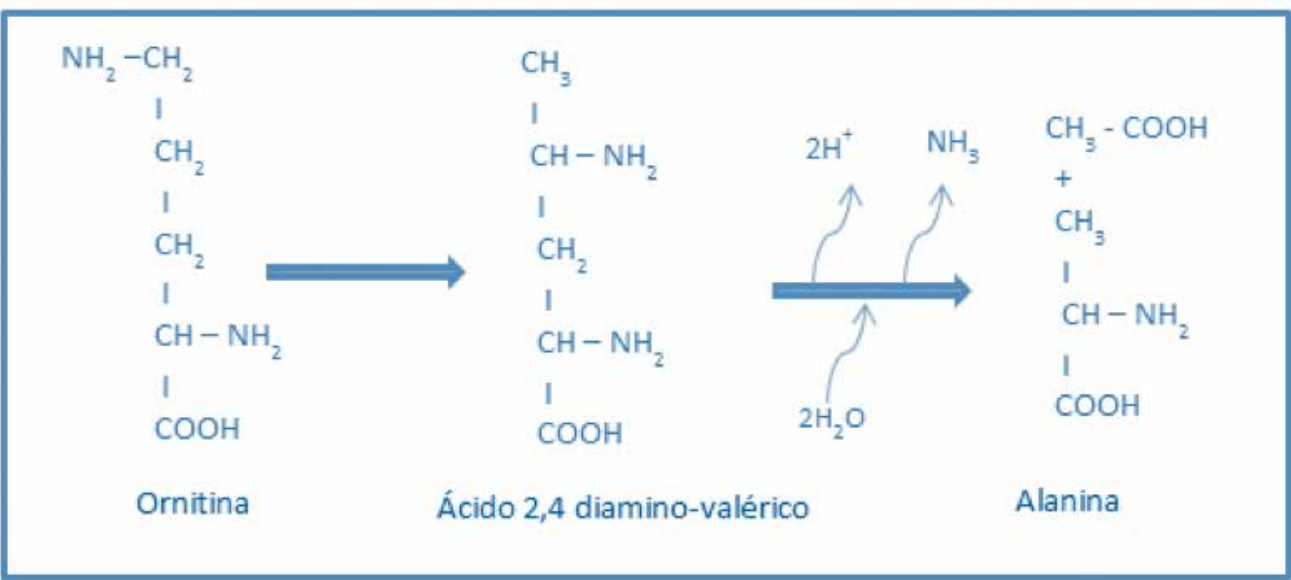

Figura 15. Proceso de oxidación de la Ornitina por Clostridium sticklandii

Modificado de: Bioquimica de los microorganismos. Ramón Parés. Antonio Juáres.2002

\section{Reacción de Stickland}

Muchos Clostridium que crecen en medios con hidrolizados de proteínas o con mezclas de aminoácidos obtienen su energía de una reacción de óxido - reducción acoplada entre dos aminoácidos o entre un aminoácido y un compuesto ternario (compuestos formados por tres átomos de distinta naturaleza), como los hidróxidos, los oxoácidos y las oxosales (60).
Esta reacción de acoplamiento, entre dos aminoácidos, se denomina reacción de Stickland y se caracteriza porque los aminoácidos por separado no se descomponen en forma rápida, mientras que la pareja de aminoácidos si lo hace, Figura 16. En este caso uno de ellos es oxidado y el otro es reducido. Esta reacción constituye la base en como las bacterias utilizan las proteínas como fuente de energía. En los Clostridium proteolíticos, la fermentación de aminoácidos más característica es la reacción de Stickland (60)

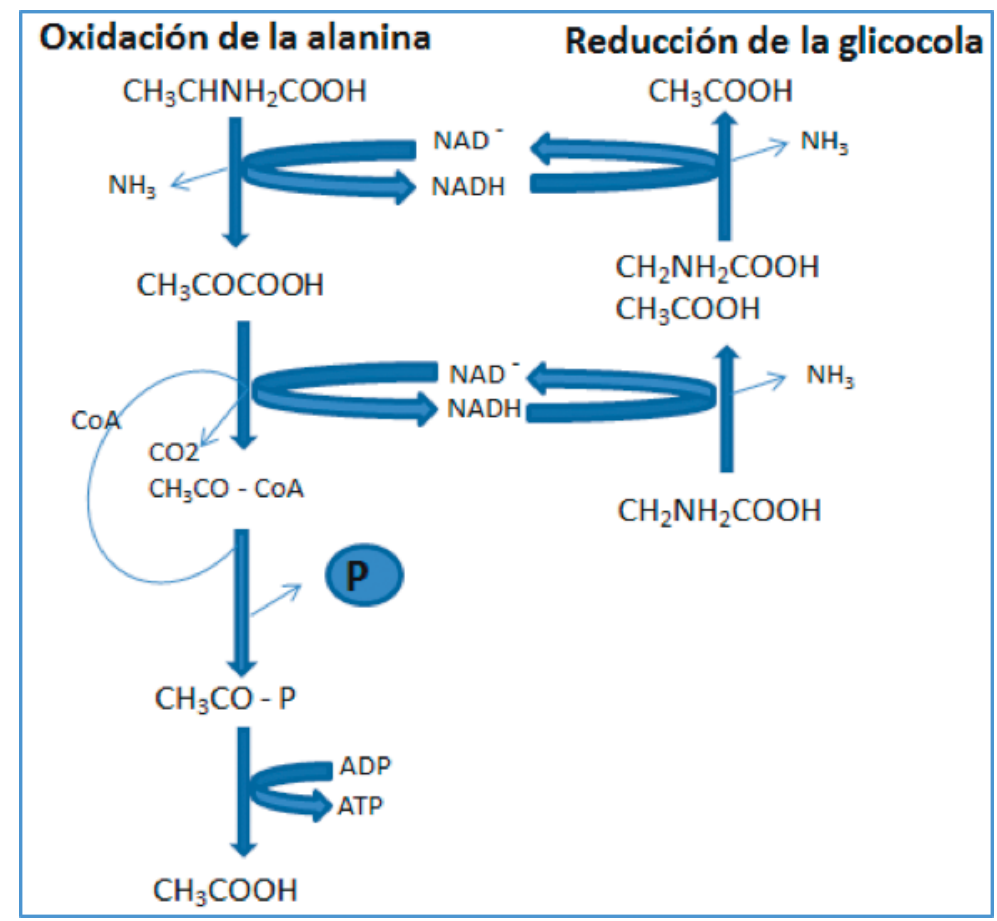

Figura 16. Mecanismo de la reacción de Stickland, con alanina como donador de electrones y glicocola como aceptor de ellos/ Corrales LC. Modificado de: Microbiología. Roger Y. Stanier. 2005 
En esta reacción el donador de electrones es la alanina, la cual es desaminada oxidativamente a piruvato, para sufrir luego una ruptura tiolítica dando acetil-CoA y $\mathrm{CO}_{2}$. El ATP se forma mediante la conversión del acetil-CoA en acetato y el NADH es reoxidado por una desaminación reductora de la glicocola a acetato.

Los aminoácidos que actúan como reductores pueden dividirse en tres grupos:

- Aminoácidos alifáticos que son más reducidos que los $\boldsymbol{\alpha}$ - cetoácidos (alanina, leucina, isoleucina, norleucina y valina).

- Aminoácidos alifáticos con el mismo grado de oxidación que los $\alpha$ - cetoácidos (serina, treonina, cisteina, metionina, arginina, citrulina y ornitina).

- Otros aminoácidos, generalmente menos oxidados que los $\alpha$ - cetoácidos (histidina, fenilalanina, triptófano, tirosina, aspartato y glutamato) Figura 17.

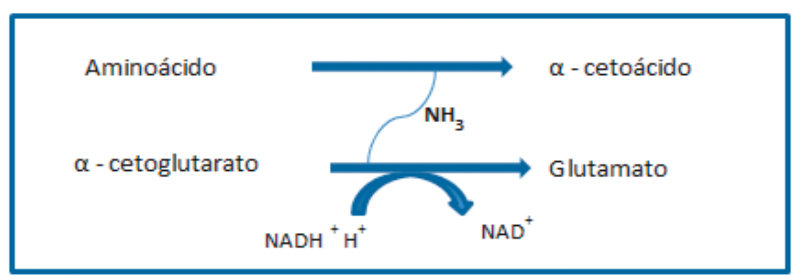

Figura 17. Reducción de un aminoácido.

Modificado de: Microbiología. Roger Y. Stanier. 2005

Las bacterias que utilizan la reacción de Stickland son Clostridium proteolíticos, entre los que se encuentran Clostridium como: C. acetobutvlicum, $C$. aerofaetidum, C. bifermentans, C. camis, C. botulinum, C. caproicum, C. indolis, C. mitelmani, C. saprotoxicum, C. sordellii, C. sporogenes, C. sticklandii, C. valerianicum, C. ghoni y C. hystoliticum.

En la Figura18, se observa: (1) Sistema de la Laminoácido deshidrogenasa. (2) Sistema de la 2-cetoacido deshidrogenasa. Requiere lipoamida, TPP y HS - CoA. Si R es un grupo metilo y $\mathrm{R}$ un átomo de hidrogeno, entonces el esquema representa la fermentación conjunta de la glicina y de la alanina que proporciona acetato y $\mathrm{CO}_{2}$ según la siguiente estequiometria.

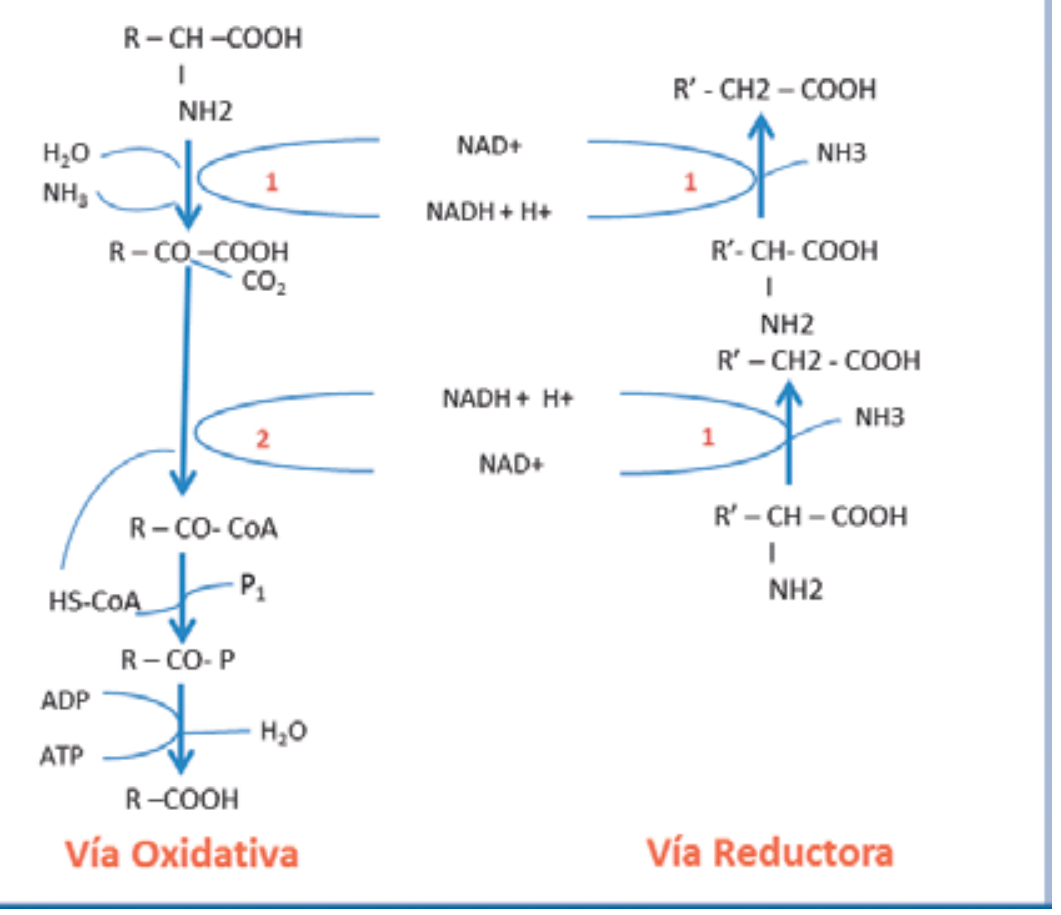

Figura 18. Reacción de Stickland / Corrales LC.

Tomado de: Lilian Frioni. Procesos Microbianos Tomo II 1999(61). 


\section{La fermentación de alanina y glicina}

$$
\text { Alanina }+2 \text { Glicina } \stackrel{2 \mathrm{H}_{2} \mathrm{O}}{\longrightarrow} 3 \text { Acetato }+\mathrm{CO}_{2}+3 \mathrm{NH}_{3}
$$

Figura 19. Reacción química de la fermentación de alanina y glicina.

Tomado de J. Koolman y K-H Rohm, Bioquímica: Texto y Atlas. 2004 (62, 63).

\section{Reacción de fermentación de un aminoácido junto a un cetoácido}

Clostridium propionicum usa la reacción de Stickland para metabolizar la $\beta$-alanina a ácido propiónico, utilizando el piruvato como oxidante.
El conjunto del sistema degradativo se presenta en la Figura 20. Un sistema degradativo similar se encuentra en Clostridium aminobutyricum que convierte $\boldsymbol{\alpha}$ - aminobutirico y como en el caso anterior también se produce acetato (64).

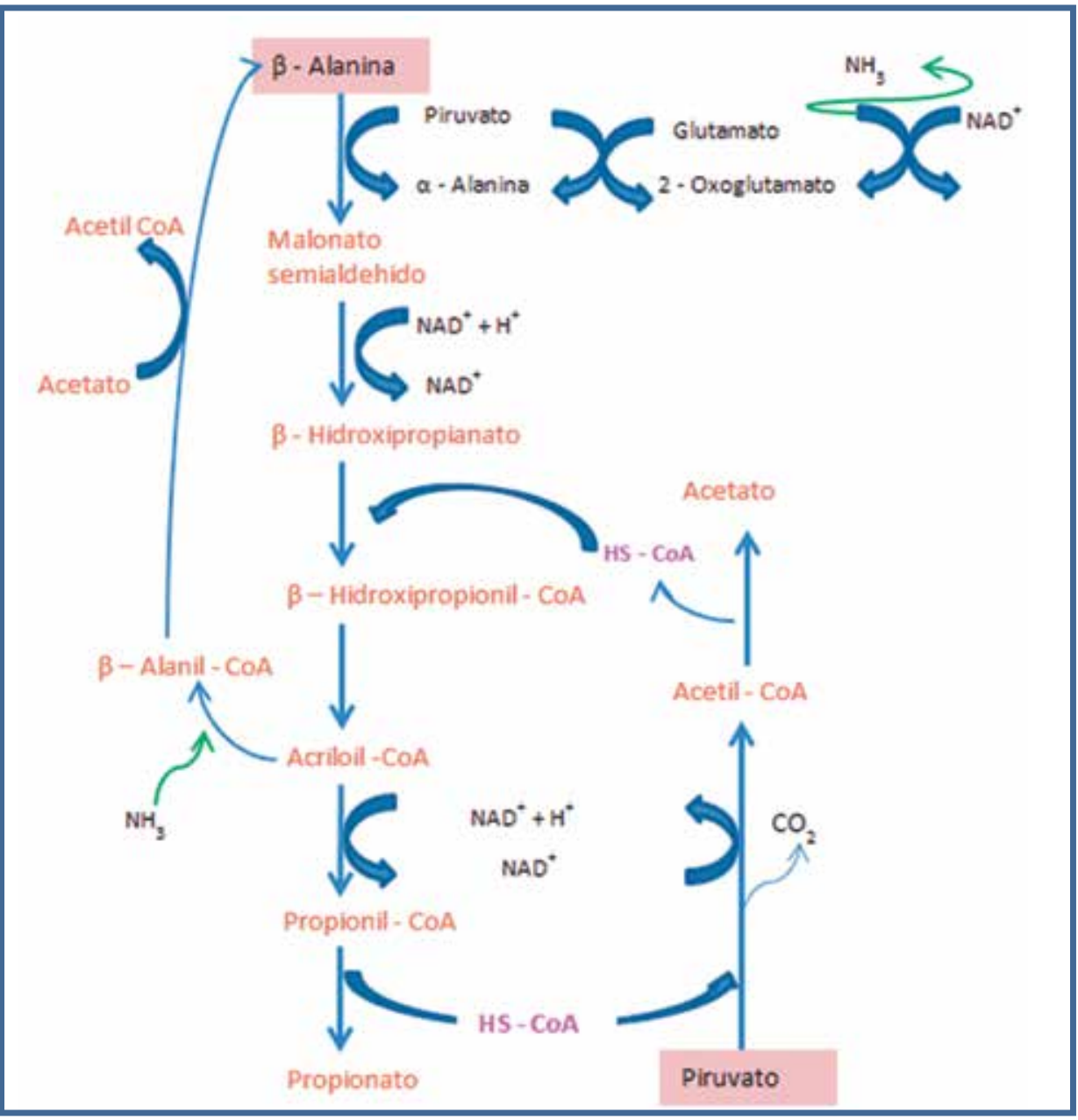

Figura 20. Reacción de Fermentación de un Aminoácido junto a un Cetoácido/ L. Corrales. Tomado de: bioquimica de los microorganismos. Ramón Parés. Antonio Juáres.2002 


\section{Descarboxilación de aminoácidos}

Cierto número de bacterias catalizan la descarboxilación de algunos aminoácidos según la siguiente reacción, Figura 21.

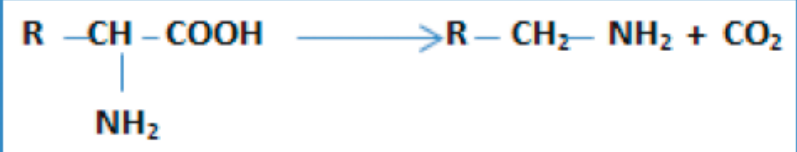

Figura 21. Proceso de descarboxilación por parte de ciertas bacterias.

Modificado de: bioquímica de los microorganismos. Ramón Parés. Antonio Juáres.2002
Los aminoácidos más frecuentemente descarboxilados de esta forma son histidina, arginina, ornitina, lisina, triptófano y glutamato.
La descarboxilación de la lisina genera cadaverina, sustancia básica de olor muy desagradable, Figura 22.

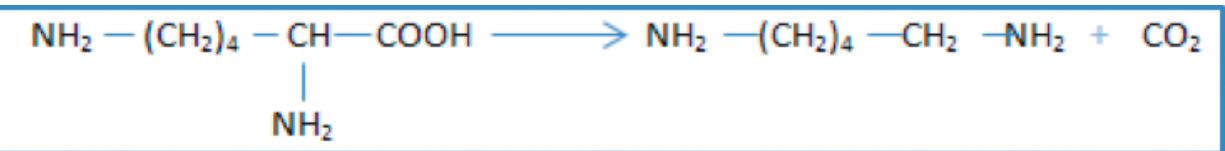

Figura 22. Descarboxilación de la Lisina y producción de Cadaverina Modificado de: bioquímica de los microorganismos. Ramón Parés. Antonio Juáres.2002

La reacción de descarboxilación se lleva a cabo principalmente en medio relativamente ácido. Las bases producidas tienden a elevar el $\mathrm{pH}$, estas reacciones de descarboxilación de aminoácidos han sido utilizadas por su significación taxonómica (64).

\section{Conclusiones}

La vida en la Tierra se debe en gran parte a las interacciones bacterianas presentes hoy en día (mutualismo y sinergismo), ya que éstas introdujeron diferentes maneras de supervivencia. Estas interacciones permiten que en el planeta toda materia sea reutilizada, gracias a que las bacterias utilizan diversos compuestos para la obtención de energía necesaria para llevar a cabo todos los procesos biológicos y químicos requeridos para su desarrollo y que les demanda el microambiente en donde se encuentran.
La utilidad del metabolismo de las bacterias anaerobias, y los procesos bioquímicos que realizan, se ve reflejado en diferentes escenarios de la vida en el planeta, principalmente se observa a nivel industrial con la producción de variedad de compuestos, como el metano para la generación de combustibles orgánicos, con el fin de producir energía renovable lo cual contribuye a la conservación del medio ambiente. Así mismo, procesos en los que participan conformando consorcios para el tratamiento y /o recuperación de aguas contaminadas y sobre materias orgánicas para su degradación a fuentes de energía posiblemente renovables.

Los diferentes ciclos biogeoquímicos en los que participan estos microorganismos hacen que las bacterias aerobias puedan desempeñarse adecuadamente, es allí donde se mencionan los procesos fermentativos como el metabolismo de los animales rumiantes donde bacterias metanogénicas 
contribuyen en la degradación de la materia orgánica y por ende con la nutrición animal. Otros procesos destacados son los de fijación, amonificación o nitrificación que se dan en el ciclo del nitrógeno para que de esta manera pueda ser usado como alimento para las plantas, que a gran escala beneficia la producción de recursos vegetales para consumo humano, animal, industrial y la sostenibilidad del medio ambiente.

\section{Referencias}

1. Margulis L, Sagan D. Cuatro mil años de evolución desde nuestros ancestros microbianos. Barcelona: Microcosmos; 1995.

2. Winn (h.), Allen S, Janda W, Koneman E, Procop G, Schreckenberger P, Woods G. Bacterias anaerobias. En: Elmer W. Koneman . Koneman diagnóstico microbiológico texto y atlas en color. 6a ed. Buenos Aires: Editorial Médica Panamericana; 2006. p. 836- 897.

3. Montoya HH. Microbiología básica para el área de la salud y afines. 2a ed. Medellín- Colombia: editorial universidad de Antioquia; 2008.

4. Corrales LC, Ávila SL, Estupinán SM. Bacteriología Teoría y Práctica. Bogotá- Colombia: Editorial Universidad Colegio Mayor De Cundinamarca; 2013.

5. Fernández E. La importancia de lo pequeño. Comunidades bacterianas y sociedad humana. Política y Sociedad [revista en internet]* 2002 [acceso 14 febrero 2014]; 39(3). Disponible en: http://revistas.ucm.es/index.php/POSO/article/view/POSO0202330575A

6. Pearl H, Pinckney J. A mini review of microbial consortia: their role in aquatic production and biogeochemical cycling. Microbial Ecology [revista en internet] ${ }^{*} 1996$ [acceso 28 abril 2014]. Disponible en: http://link.springer.com/article/10.1007/BF00171569\#page-1

7. Schink B. Energetics of syntrophic cooperation in methanogenic degradation. Microbiology and molecular biology reviews [revista en internet] ${ }^{*} 1997$ [acceso 14 febrero 2014]; 61 (2). Disponible en: http://mmbr.asm.org/content/61/2/262.abstract

8. Almeida A, Nafarrate E, Alvarado A, Cervantes A, Luevanos, Oropeza R, Balagurusamy N. Expresión genética en la digestión anaerobia: un paso adelante en la comprensión de las interacciones tróficas de esta biotecnología. Revista Científica de la Universidad Autónoma de Coahuila [revista en internet]* 2011 [acceso 28 febrero 2014]; 3(6). Disponible en: http:// www.posgradoeinvestigacion.uadec.mx/AQM/No.\%206/3. html

9. Schoberth SM. Biomethane, production and uses. En John Wiley \& Sons. The microbiology of anaerobic digestion. London: Turret-Weatland; 2003. p. 61-78.

10. Lorenzo Y, Obaya MC. La digestión anaerobia. Aspectos teóricos. Parte I. ICIDCA. Sobre los Derivados de la Cańa de
Azúcar [revista en internet]* 2005 [acceso 02 Marzo 2014]; 39(1). Disponible en: http://www.redalyc.org/articulo. oa?id=223120659006

11. González A, Cuadros F, Ruiz-Celma A, López-Rodríguez F. Energy-environmental benefits and economic feasibility of anaerobic codigestion of Iberian pig slaughterhouse and tomato industry wastes in Extremadura (Spain). Elsevier [revista en internet] ${ }^{*} 2013$ [acceso 02 Marzo 2014]. Disponible en: http://www.sciencedirect.com/science/article/pii/ S096085241300254X

12. Pérez A, Torres P. Índices de alcalinidad para el control del tratamiento anaerobio de aguas residuales fácilmente acidificables. Ingeniería y Competitividad [revista en internet]* 2008 [acceso 10 Marzo 2014]; 10(2). Disponible en: http://webcache.googleusercontent.com/search?q=cache:bs8vvT9B4eMJ: bibliotecadigital.univalle.edu.co/bitstream/10893/1636/1/vo $1.10 \% 2520$ no. $2 \% 2520$ art.3.pdf $+\& c d=2 \& h l=e s \& c t=c l n k \& g l$ $=\mathrm{CO}$

13. Khalida A, Arshadb M, Anjuma M, Mahmooda T, Dawsonc L. The anaerobic digestion of solid organic waste. Elsevier [revista en internet]* 2011 [acceso 10 Marzo 2014]; 31(8). Disponible en: http://www.researchgate.net/publication/51086548_The_ anaerobic_digestion_of_solid_organic_waste

14. Cajigas AA, Pérez A, Torres P. Importancia del pH y la alcalinidad en el tratamiento anaerobio de las aguas residuales del proceso de extracción de almidón de yuca. Scientia et Technica [revista en internet]* 2005. [acceso 15 Marzo 2014]; 11(27). Disponible en: http://www.redalyc.org/articulo. oa?id=84911698045

15. Torrado JR, Calixto DM, Sarmiento AE, Panqueva JH. Evaluación del molibdato y nitrato sobre bacterias sulfatoreductoras asociadas a procesos de corrosión en sistemas industriales. Revista argentina de microbiología [revista en internet] ${ }^{*}$ Marzo 2008. [acceso 10 Julio 2015]; 40(1). Disponible en: http://www.scielo.org.ar/scielo.php?pid=S032575412008000100012\&script $=$ sci_arttext

16. Decheco AC. Metabolismo microbiano. Universidad del callao. 2011. [acceso 10 Marzo 2014]. Disponible en: http:// www.unac.edu.pe/documentos/organizacion/vri/cdcitra/Informes_Finales_Investigacion/Octubre_2011/IF_DECHECO\%20EGUSQUIZA_FIPA/CAPITULO $\% 20 \mathrm{~N} \% \mathrm{BA} \% 20$ 05.pdf

17. Barton LL, Tomei FA. Characterisrics and activities of sulfatereducing bacteria. En: Larry Barton. Sulfate-Reducing Bacteria. New York: Biotechnology Handbooks; 1995. p.1-18.

18. Rodríguez E, Gamboa M, Hernández F. Bacteriología General: Principios Y Prácticas de Laboratorio. Costa Rica: Editorial Universidad de Costa Rica; 2005.

19. Diaz MC, Espitia SE, Molina F. Microbiología de la digestión anaerobia. En: Colciencias. Digestion anaerobia: una aproximación a la tecnología. $1^{a}$ ed. Colombia: Uneditorial - Instituto de biotecnología; 2002. p. 45-71.

20. Hernández A, Alfaro I, Arrieta R. Las fermentaciones. En: Alicia Hernández. Microbiología industrial. UNED; 2003. p. 37-39.

21. Campbell NA, Reece JB. Respiración celular: obtención de energía química. En: Alberto Alcocer. Biologia. $7^{a}$ ed. MadridEspaña: Panamericana; 2005. p. 170-176. 
22. Beyer ML, Walter W. Manual de química orgánica. 19ª ed. Barcelona: Reverte; 1987.

23. Vázquez HL, Dacosta O. Fermentación alcohólica: Una opción para la producción. Ingeniería Investigación y Tecnología [revista en internet]* 2007 [acceso 11 Abril 2014]; 8(4). Disponible en: http://www.journals.unam.mx/index.php/ingenieria/article/view/13478

24. Vincent MC, Álvarez S, Zaragozá JL. Química industrial orgánica. Valencia: Universidad Politécnica de Valencia; 2006.

25. Yuan Kun L. Microbial Biotechnology: principles and Applications. Second edition. London. World Scientific Publishing Co. Pte. Ltd; 2006.

26. Macfarlane GT, Macfarlane S. Microbiota humana colon: la ecología, la fisiología y el potencial metabólico de las bacterias intestinales. Scand J. Gastroenterol Suppl [revista en internet]* 1997 [acceso 28 Marzo 2014]. Disponible en: http://www. ncbi.nlm.nih.gov/pubmed/9145437

27. Devaraj S, Hemarajata P, Versalovic J. La microbiota intestinal humana y el metabolismo corporal: Implicaciones con la obesidad y la diabetes. Acta bioquímica clínica latinoamericana [revista en internet]* 2013 [acceso 30 Mayo 2014]; 47(2). Disponible en: http://www.scielo.org.ar/scielo.php?pid=S032529572013000200019\&script=sci_arttext

28. Meulen RV, Avonts L, Vuyst LD. Short Fractions of Oligofructose Are Preferentially Metabolized by Bifidobacterium animalis DN-173 010. Applied and environmental microbiology [revista en internet]* 2004 [acceso 30 Mayo 2014]; 70 (4). Disponible en: http://www.ncbi.nlm.nih.gov/pmc/articles/PMC383053/

29. Jaramillo JJ, Cardona CA. Análisis de la producción de biobutanol en la fermentación acetobutilica con clostridium saccharoperbutylacetonicum N1-4 ATCC13564. [revista en internet] ${ }^{*}$ [acceso 30 junio 2014];; 58. Disponible en: http:// aprendeenlinea.udea.edu.co/revistas/index.php/ingenieria/article/view/14597/12761

30. Shinto H, Tashiro Y, Yamashita M, Kobayashi G, Sekiguchi T, Hanai T, Kuriya T, Okamoto M, Sonomoto K. Kinetic modeling and sensitivity analysis of Acetone-Butanol-Ethanol production. Journal of Biotechnology. [revista en internet]* 2007 [acceso 15 Junio 2014]; 131 (1). Disponible en: http://www. sciencedirect.com/science/article/pii/S0168165607003549

31. Tsiung S, Hsu, Tian Yang S. Propionic acid fermentation of lactose by Propionibacterium acidipropionici: effects of $\mathrm{pH}$. Biotechnol Bioeng. [revista en internet]* septiembre 1991 2007 [acceso 30 Junio 2014]; 38 (6). Disponible en: http:// www.ncbi.nlm.nih.gov/pubmed/18604876

32. Kośmider A, Drożdżyńska A, Blaszka K, Leja K, Czaczyk K. Propionic Acid Production by Propionibacterium freudenreichii ssp. shermanii Using Crude Glycerol and Whey Lactose Industrial Wastes. Journal of environmental studies [revista en internet]* 2010 [acceso 18 julio 2014]; 19 (6). Disponible en: http://www.pjoes.com/abstracts/2010/Vol19/No06/15.html

33. Wang Z, Tian Yang S. Propionic acid production in glycerol/ glucose co-fermentation by Propionibacterium freudenreichii subsp. Shermanii. Bioresource Technology [revista en internet] ${ }^{*}$ June 2013 [acceso 18 julio 2014]; 137. Disponible en: http://www.ncbi.nlm.nih.gov/pubmed/23584412
34. Allison C, Macfarlane GT. Dissimilatory nitrate reduction by Propionibacterium acnes. Appl Environ Microbiol. 1989 Nov; 55(11): 2899-2903. Disponible en: http://www.ncbi.nlm. nih.gov/pmc/articles/PMC203188/?page=1

35. Parés R, Juárez A. Bioquímica de los microorganismos. Barcelona España: Reverte S.A; 1997.

36. Martí N. Phosphorus Precipitation in Anaerobic Digestion Process. Boca Raton, Florida USA. Universal-Publishers; 2006.

37. Drake HL. Acetogenesis. New York: Springer Science \& Business Media; 2012.

38. Acuña PA, Ángel LS, Montoya EB, Corrales LC, Sánchez LC. Aislamiento e identificación de microorganismos del género Methanococcus y Methanobacterium de cuatro fuentes de Bogotá D.C. NOVA [revista en internet]* Diciembre 2008 [acceso 30 julio 2014]; 6 (10). Disponible en: http://webcache.googleusercontent.com/search?q=cache:JY25opZ3M8wJ:www. unicolmayor.edu.co/invest_nova/NOVA/NOVA10_ARTORIG5_METHAN.pdf $+\& \mathrm{~cd}=1 \& \mathrm{hl}=\mathrm{es} \& \mathrm{ct}=\mathrm{clnk} \& \mathrm{gl}=\mathrm{co}$

39. Carmona JC, Bolívar DM, Giraldo LA. El gas metano en la producción ganadera y alternativas para medir sus emisiones y aminorar su impacto a nivel ambiental y productivo. Revista Colombiana de Ciencias Pecuarias [revista en internet]* 2005 [acceso 15 Agosto 2014]; 18 (1). Disponible en: http://rccp. udea.edu.co/index.php/ojs/article/view/6

40. Khalida A, ArshadbM, Anjuma M, Mahmooda T, Dawsonc T. The anaerobic digestion of solid organic waste. Elsevier,Waste Management [revista en internet] ${ }^{*}$ August 2011 [acceso 20 Agosto 2014]; 31(8). Disponible en: http://www.sciencedirect.com/science/article/pii/S0956053X11001668

41. Claire A, Ragsdale SW. Methods in Methane Metabolism: Methanogenesis. 1a ed. USA: Academic Press of Elsevier; 2011

42. Karakashev D, Batstone JD, Angelidaki I. Influence of Environmental Conditions on Methanogenic Compositions in Anaerobic Biogas Reactors. Applied and environmental microbiology [revista en internet]* 2005 [acceso 10 Agosto 2014]; 71(1). Disponible en: http://www.ncbi.nlm.nih.gov/pmc/articles/PMC544252/

43. Madigan MT, Martinko JM, Parker J. Brock biology of Microorganisms. 8a ed. New Jersey: Hardcover; 1998.

44. Prescott LM, Harley JP, Klein DA. Microbiología. 4a ed. Madrid: McGraw-Hill-Interamericana; 1999.

45. Mejía GM. Digestión anaerobia. Yucatán, México: Mérida; 1996.

46. Ferrer Y, Pérez H. Los microorganismos en la digestión anaerobia y la producción de biogás. Consideraciones en la elección del inóculo para el mejoramiento de la calidad y el rendimiento. ICIDCA [revista en internet] ${ }^{*}$ enero-abril 2010. [acceso 20 Agosto 2014]; 43(1). Disponible en: www.redalyc.org/ pdf/2231/223120681002.pdf

47. Gallegos M, Celis LB, Razo-Flores E. Competencia por sustrato durante el desarrollo de biomasa sulfatorreductora a partir de un lodo metanogénico en un reactor UASB. Revista internacional de contaminación ambiental [revista en internet]* Mayo 2010. [acceso 20 Mayo 2015]; 26(2). Disponible en: http://www.scielo.org.mx/scielo.php?script=sci_arttext\&pid $=$ S0188-49992010000200002 
48. Nelson DL, Cox MM. Principios de Bioquímica. 4ª ed. Barcelona: Omega; 2005.

49. Madigan MT, Martinko JM, Parker J. Microbiología de los microorganismos. 13a ed. Benjamin Cummings; 2010.

50. Flores AC, Rodríguez R, Contreras JC. La fijación biológica de nitrógeno por microorganismos; su importancia en la agricultura y conservación del medio ambiente. Cienciacierta [revista en internet]* Julio - septiembre 2009 [acceso 22 Agosto 2014]; 5(19). Disponible en: http://www.researchgate.net/ publication/233387183_La_fijacin_biolgica_de_nitrgeno_ por_microorganismos_su_importancia_en_la_agricultura_y_ conservacin_del_medio_ambiente

51. Wagner SC. Biological Nitrogen Fixation. Nature Education Knowledge. [revista en internet]* 2011. [acceso 22 Marzo 2015]; 3(10). Disponible en: http://www.nature.com/scitable/ knowledge/library/biological-nitrogen-fixation-23570419

52. Rodríguez C, Sevillano F, Subramaniam P. La Fijación De Nitrógeno Atmosférico Una Biotecnología En La Producción Agraria. $1^{\text {a }}$ ed. Subramaniam; 1985.

53. Urzúa H. Beneficios de la Fijación Simbiótica de Nitrógeno en Chile. Pontificia Universidad Católica de Chile. Ciencia e Investigación Agraria [revista en internet]* Agosto 2005 [acceso 10 Septiembre 2014]; 32(2). Disponible en: http://www.rcia. uc.cl/index.php/rcia/article/view/313/239+\&cd=1\&hl=es\&ct $=\mathrm{clnk} \& \mathrm{gl}=\mathrm{co}$

54. Soto L, Baca BE. Mecanismos de Protección de la Nitrogenasa a la Inactivación por Oxígeno. Revista Latinoamericana de $\mathrm{Mi}$ crobiología [revista en internet] ${ }^{*} 2001$. [acceso 03 noviembre 2014]. Disponible en: www.medigraphic.com/pdfs/lamicro/ mi-2001/mi011f.pdf
55. Postgate JR. The fundamentals of nitrogen fixation. Cambridge-Inglaterra: Ilustrada; 1982.

56. Barea JM. Cuantificación de la fijación biológica de $\mathrm{N}$ mediante el uso de N15. En fijación y movilización biológica de nutrientes. Madrid-Espańa: RAYCAR S.A 1991

57. Peláez HA, Prada MC, Caicedo G, Moreno C, Márquez MA. Influencia de la relación inicial de $\mathrm{Fe} 3+/ \mathrm{Fe} 2+$, en un proceso de biodesulfurización de carbones en suspensión. Revista internacional de contaminación ambiental [revista en internet] ${ }^{*}$ Mayo 2013. [acceso 23 Mayo 2015]; 29(2). Disponible en: http://www.scielo.org.mx/scielo.php?pid=S018849992013000200007\&script=sci_arttext

58. Peña A, Arroyo A, Gómez A, Tapia R, Gómez. Bioquímica. $11^{\mathrm{a}}$ ed. México D.F: Limusa; 2004.

59. Mathews CK, Holde KE, Appling DR. Biochemistry. 4a ed. Pearson; 2012

60. Stanier RY, Ingraham JL, Wheelis ML, Painter PR. Microbiología 2a ed. Barcelona - España: Reverte; 2005.

61. Frioni L. Procesos Microbianos Tomo II. Córdoba: Editorial de la fundación Universidad Nacional de Río Cuarto; 1999.

62. Koolman. J, Rohm KH. Bioquímica: Texto y Atlas. 3a ed. Buenos Aires; Panamericana; 2004.

63. Reggiani R, Bertani A. Anaerobic Amino Acid Metabolism. Russian Journal of Plant Physiology [revista en internet]* November 2003 [acceso 28 noviembre 2014]; 50(6). Disponible en: http://link.springer.com/article/10.1023\%2FB\%3ARUPP .0000003270.33010.22\#page-1

64. Audesirk T, Audesirk G, Byers BE. Biología: La vida en la tierra. $6^{a}$ ed. México: Pearson; 2003. 